\title{
Seasonal variations of thermocline circulation and ventilation in the Indian Ocean
}

\author{
Yuzhu You \\ Center for Climate System Research, University of Tokyo, Tokyo \\ Laboratoire d'Océanographie Physique, Muséum National d'Histoire Naturelle, Paris
}

\begin{abstract}
Two seasonal hydrographic data sets, including temperature, salinity, dissolved oxygen, and nutrients, are used in a mixing model which combines cluster analysis with optimum multiparameter analysis to determine the spreading and mixing of the thermocline waters in the Indian Ocean. The mixing model comprises a system of four major source water masses, which were identified in the thermocline through cluster analysis. They are Indian Central Water (ICW), North Indian Central Water (NICW) interpreted as aged ICW, Australasian Mediterranean Water (AAMW), and Red Sea Water (RSW)/Persian Gulf Water (PGW). The mixing ratios of these water masses are quantified and mapped on four isopycnal surfaces which span the thermocline from 150 to $600 \mathrm{~m}$ in the northern Indian Ocean, on two meridional sections along $60^{\circ} \mathrm{E}$ and $90^{\circ} \mathrm{E}$, and on two zonal sections along $10^{\circ} \mathrm{S}$ and $6^{\circ} \mathrm{N}$. The mixing ratios and pathways of the thermocline water masses show large seasonal variations, particularly in the upper $400-500 \mathrm{~m}$ of the thermocline. The most prominent signal of seasonal variation occurs in the Somali Current, the western boundary current, which appears only during the SW (summer) monsoon. The northward spreading of ICW into the equatorial and northern Indian Ocean is by way of the Somali Current centered at $300-400 \mathrm{~m}$ on the $\sigma_{\theta}=26.7$ isopycnal surface during the summer monsoon and of the Equatorial Countercurrent during the NE (winter) monsoon. More ICW carried into the northern Indian Ocean during the summer monsoon is seen clearly in the zonal section along $6^{\circ} \mathrm{N}$. NICW spreads southward through the western Indian Ocean and is stronger during the winter monsoon. AAMW appears in both seasons but is slightly stronger during the summer in the upper thermocline. The westward flow of AAMW is by way of the South Equatorial Current and slightly bends to the north on the $\sigma_{\theta}=26.7$ isopycnal surface during the summer monsoon, indicative of its contribution to the western boundary current. Outflow of RSW/PGW seems effectively blocked by the continuation of strong northward jet of the Somali Current along the western Arabian Sea during the summer, giving a rather small contribution of only up to $20 \%$ in the Arabian Sea. A schematic summer and winter thermocline circulation emerges from this study. Both hydrography and water - mass mixing ratios suggest that the contribution of the water from the South Indian Ocean and from the Indo-Pacific throughflow controls the circulation and ventilation in the western boundary region during the summer. However, during the winter the water is carried into the eastern boundary by the Equatorial Countercurrent and leaks into the eastern Bay of Bengal, from where the water is advected into the northwestern Indian Ocean by the North Equatorial Current. The so-called East Madagascar Current as a southward flow occurs only during the summer, as is suggested by both hydrography and water-mass mixing patterns from this paper. During the winter (austral summer) the current seems reversal to a northward flow along east of Madagascar, somewhat symmetrical to the Somali Current in the north.
\end{abstract}

\section{Introduction}

The main thermocline layer of the ocean is in general treated as a layer that is not subject to seasonal variability, because it is situated well below the seasonal surface layer. Between these two layers there is a density transition which Defant [1961] called the "barrier layer." However, since climatology of the Indian Ocean is dominated by two distinct reversal monsoons, the southwest (or summer) monsoon and the northeast (or winter) monsoon, seasonal variations throughout the main thermocline of the Indian Ocean are significant and cannot be ignored. Colborn [1975] found that monsoonal effect on thermal structure of the northern

Copyright 1997 by the American Geophysical Union.

Paper number 96JC03600.

0148-0227/97/96JC-03600\$09.00
Indian Ocean can reach as deep as $500 \mathrm{~m}$, while Wyrtki [1973] suggested that impact of the southwest monsoon is noticeable as deep as $1000 \mathrm{~m}$ at the Somali Current region. Tchernia [1980] proposed an even deeper effect of seasonal variation on water mass properties down to $2000 \mathrm{~m}$. Probably the most profound effect of seasonal monsoons is on the Somali Current, which appears only during the summer. The great differences among the estimated transports from the Pacific to the Indian Ocean, ranging from 1.7 Sv [Wyrtki, 1961] to $18 \mathrm{~Sv}$ [Cox, 1975, after Gordon, 1986]. The latter also suggests that strong seasonal variation must play a role in thermocline structures.

Several factors, including distinct seasonal monsoons and the effects of a complicated geography, the northern Indian Ocean being blocked by the Eurasian landmass, the lack of a Subtropical Convergence Zone, and an interoceanic throughflow including its distinct hydrological front, lead to the formation of a unique thermocline water - mass structure in the Indian Ocean. Sverdrup 
et al. [1942] identified three water masses and discussed their formation mechanisms in the main thermocline of the Indian Ocean: (1) Red Sea Water (RSW), formed in the Red Sea; (2) Indian Central Water (ICW, also called Subtropical Subsurface Water by Warren et al. [1966] and Subantarctic Mode Water by McCartney [1977]) formed in latitudes $40^{\circ}-45^{\circ} \mathrm{S}$ during late winter by convective overturning [Wyrtki, 1973; Colborn, 1975]; and (3) Indian Equatorial Water (IEW), formed in the western equatorial region through some unspecified mechanism. Mamayev [1975] added two more water masses to the Indian Ocean north of $40^{\circ} \mathrm{S}$ : Bengal Bay Water (BBW), which is only found in the surface layer, and Timor Sea Water (called Australasian Mediterranean Water (AAMW) by You and Tomczak [1993]), which originates in the deep basins of the Indonesian archipelago. The latter was missed by Sverdrup et al. [1942] because they lacked data for the eastern Indian Ocean [Colborn, 1975]. In a recent review, Emery and Meincke [1986] included another water mass, Arabian Sea Water (ASW), which is influenced by outflow of Persian Gulf Water (PGW) and is distinguished from RSW. These water masses which form the basic large-scale structure of the thermocline in the Indian Ocean north of $40^{\circ} \mathrm{S}$ are listed in Table 1 , which also includes a compendium of the same water masses with different names according to various authors. A relatively recent generalized Indian Ocean temperature - salinity (T-S) diagram of Emery and Meincke [1986] is shown in Figure 1. There is only one water mass in Table 1 that we have not mentioned yet, the North Indian Central Water (NICW), which will be discussed later.

A closer examination of these water masses, based on their regions of formation, suggests that the main thermocline of the Indian Ocean north of $40^{\circ} \mathrm{S}$ is actually dominated by only three source water masses, ICW, AAMW, and RSW/PGW. Sharma [1976], Quadfasel and Schott [1982], and You and Tomczak [1993] have argued that the IEW of Sverdrup et al. [1942] is actually a mixture of water masses from the northern and southern Indian Ocean and from the Pacific. The BBW defined by Mamayev [1975] is the result of excess precipitation and river runoff over evaporation resulting in a low salinity (between 32 and $33 \mathrm{psu}$ ). This low salinity causes it to be isolated from the water in the main thermocline by a sharp halocline located

Table 1. An Inventory of Water Mass Definitions in the Thermocline of the Indian Ocean

\begin{tabular}{|c|c|c|c|c|}
\hline \multirow{2}{*}{ Water Mass } & \multirow[t]{2}{*}{ Study } & \multicolumn{2}{|c|}{ T-S Characteristics } & \multirow[t]{2}{*}{ Notes } \\
\hline & & $\mathrm{T},{ }^{\circ} \mathrm{C}$ & S, psu & \\
\hline Indian Central Water (ICW) & $\begin{array}{l}\text { Sverdrup et al. }[1942] \\
\text { Mamayev }[1975] \\
\text { Emery and Meincke }[1986] \\
\text { Warren et al. }[1966] \\
\text { McCartney }[1977]\end{array}$ & $\begin{array}{l}7.00-16.00 \\
16.00 \\
8.00-25.00 \\
7.00-15.00\end{array}$ & $\begin{array}{l}34.70-35.70 \\
35.60 \\
34.60-35.80 \\
34.70-35.50\end{array}$ & $\begin{array}{l}\text { Formed by late winter } \\
\text { convective overturning at } \\
40^{\circ}-45^{\circ} \mathrm{S}\end{array}$ \\
\hline \multirow{2}{*}{$\begin{array}{l}\text { Australasian Mediterranean } \\
\text { Water (AAMW) }\end{array}$} & You and Tomczak [1993] & $5.55-14.89$ & $34.52-34.77$ & \\
\hline & $\begin{array}{l}\text { Mamayev [1975] } \\
\text { Emery and Meincke [1986] } \\
\text { Wyrtki }[1961] \\
\text { Rochford }[1966]\end{array}$ & $\begin{array}{l}25.00 \\
8.00-23.00\end{array}$ & $\begin{array}{l}34.50 \\
34.40-35.00\end{array}$ & After Warren [1981] \\
\hline $\begin{array}{l}\text { North Indian Central Water } \\
\text { (NICW) }\end{array}$ & You and Tomczak [1993] & $7.80-15.72$ & $34.84-35.10$ & $\begin{array}{l}\text { Defined as thermocline } \\
\text { water below the surface } \\
\text { water at the Bay of Bengal. } \\
\text { The same as Gordon but } \\
\text { defined as aged ICW }\end{array}$ \\
\hline Red Sea Water (RSW) & $\begin{array}{l}\text { Sverdrup et al. [1942] } \\
\text { Mamayev [1975] }\end{array}$ & $\begin{array}{l}>7.00 \\
23.00\end{array}$ & $\begin{array}{l}>35.00 \\
40.00\end{array}$ & $\begin{array}{l}\text { Defined as oxygen minimum } \\
\text { core. } \\
\text { Defined as intermediate } \\
\text { water. }\end{array}$ \\
\hline Bengal Bay Water (BBW) & $\begin{array}{l}\text { Mamayev [1975] } \\
\text { Emery and Meincke [1986] }\end{array}$ & $\begin{array}{l}25.00 \\
25.00-29.00\end{array}$ & $\begin{array}{l}33.80 \\
28.00-35.00\end{array}$ & $\begin{array}{l}\text { Defined as surface low- } \\
\text { salinity water. } \\
\text { Defined as surface low- } \\
\text { salinity water. }\end{array}$ \\
\hline Arabian Sea Water (ASW) & Emery and Meincke [1986] & $24.00-30.00$ & $35.50-36.80$ & \\
\hline \multirow{2}{*}{$\begin{array}{l}\text { Indian Equatorial Water } \\
\text { (IEW) }\end{array}$} & Sverdrup et al. [1942] & $5.00-16.00$ & $34.90-35.20$ & \\
\hline & $\begin{array}{l}\text { Mamayev [1975] } \\
\text { Emery and Meincke [1986] }\end{array}$ & $\begin{array}{l}25.00 \\
8.00-23.00\end{array}$ & $\begin{array}{l}35.30 \\
34.60-35.00\end{array}$ & \\
\hline
\end{tabular}

a. Called South Indian Subtropical Water by Mamayev [1975], South Indian Central Water by Emery and Meincke [1986], Subantarctic Mode Water by McCartney [1977], and Subtropical Subsurface Water by Warren et al. [1966].

b. Called Timor Sea Water by Mamayev [1975], Banda Intermediate Water by Rochford [1966], Banda Sea Water by Wyrtki [1961], and Indonesian Upper Water by Emery and Meincke [1986]. 


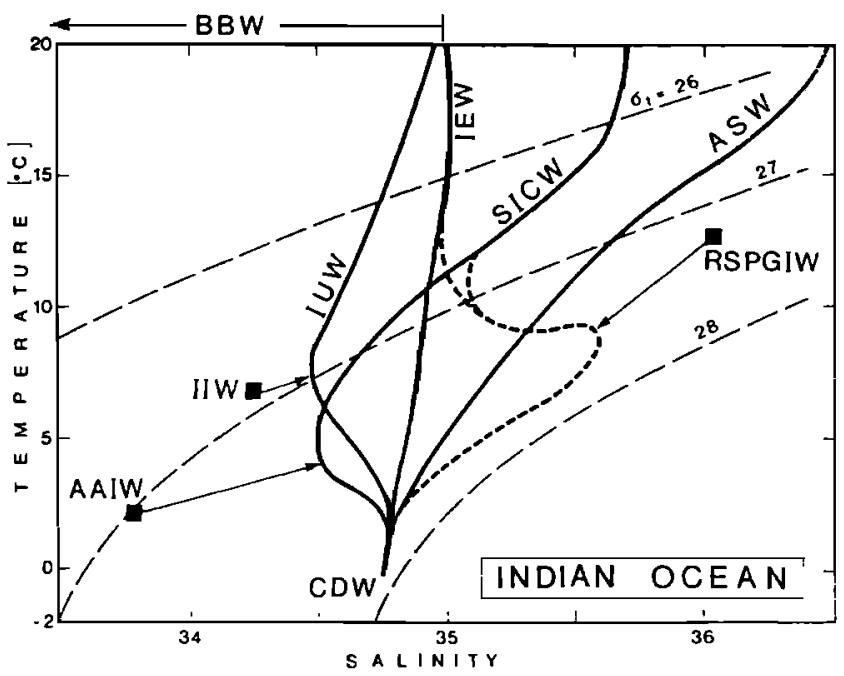

Figure 1. A generalized T-S diagram for the main water masses in the Indian Ocean. The water masses are abbreviated as follow: BBW, Bengal Bay Water; ASW, Arabian Sea Water; IEW, Indian Equatorial Water; IUW, Indonesian Upper Water; SICW, South Indian Central Water; AAIW, Antarctic Intermediate Water; IIW, Indonesian Intermediate Water; RSPGIW, Red Sea - Persian Gulf Intermediate Water; and CDW, Circumpolar Deep Water. The figure is adopted from Emery and Meincke [1986, their original Figure 5, permitted by Gauthier - Villars Editeur].

between 50 and $100 \mathrm{~m}$. Therefore, BBW defined by Mamayev [1975] is clearly restricted to only the surface layer (also see Figure 1) and will be excluded from the discussion of the main thermocline water in this paper. AAMW, also known as the Banda Intermediate Water according to Rochford [1966], is a major water mass of the world ocean and, as part of the warm water route of North Atlantic Deep Water (NADW) return flow, plays a vital role in Gordon's [1986] global model of thermocline circulation. AAMW shows as a tongue of low salinity and high silicate extending westward from Indonesia in the International Indian Ocean Expedition (IIOP) atlas [Wyrtki, 1971]. ICW is formed at the surface in late winter at latitudes $40^{\circ}-45^{\circ} \mathrm{S}$. As a result of subduction processes and subsequent mixing, the property relationships of ICW are nearly linear [Tomczak and Large, 1989]. ASW is actually a mixture of PGW and RSW [You and Tomczak, 1993]. According to Sharma [1976] the effect of PGW on thermocline water in the Arabian Sea is relatively smaller than that of RSW. You and Tomczak [1993] found, from an annual mean data set, that the influence of RSW in the upper thermocline is mainly restricted to the Arabian Sea, where it contributes up to $30 \%$ to the thermocline water. In contrast, Olson et al. [1993], using chlorofluorocarbon (CFC) data, found an even smaller contribution of RSW, less than $10 \%$.

From the preceding brief discussion of water mass structure, three water masses, IEW, BBW and ASW, can be excluded here in view of their formation sources. The discussion in this paper concentrates on main thermocline water itself. RSW and PGW are considered as a joint source water mass (even though PGW is not listed in Table 1), since they have similar water mass characteristics. Recently, You and Tomczak [1993] introduced a virtual water mass, NICW, consisting of aged ICW from the main thermocline layer in the Bay of Bengal below BBW. They argued that the introduction of this water mass is required by their optimum multiparameter (OMP) analysis, although it is not defined as an independent source water mass because it lacks a common formation process. They found that when they did not include NICW in their mixing model they derived a totally different water - mass contribution which could not be interpreted physically. Using an isopycnal-mixing-dominated surface with three conservative tracers (temperature, salinity, and initial phosphate) they showed that NICW is indeed the aged ICW (see You and Tomczak [1993] and their Figure A2). Gordon [1986] used NICW to symbolically represent the North Indian thermocline water. Thus from Table 1 a total of four water masses, ICW, NICW, AAMW, and RSW/PGW, are chosen to define thermocline circulation and ventilation in the Indian Ocean. The characteristics of these water masses in T-S diagrams and in other property-property diagrams of temperature against oxygen and nutrients are shown in Figure 8. A detailed description of the definitions of these water masses will be given in section 4. Among these source water masses, RSW/PGW contributes the least. Because the northern Indian Ocean does not have a Subtropical Convergence Zone, RSW/PGW has limited sources. In addition, as NICW is considered a water mass of aged ICW, the thermocline water of the northern Indian Ocean has to be replenished from the tropics or even farther south. Warren et al. [1966] seem to be the first to put forward the idea that the thermocline of the northern Indian Ocean may be ventilated from the south. Colborn [1975] noted that there is some degree of mixing between BBW and AAMW in the Bay of Bengal and pointed out that some diapycnal mixing must occur in the northern Indian Ocean. Toole and Warren [1993] suggested that the deep and bottom waters could be largely converted to thermocline and surface waters. Recently, You [1996] found strong dianeutral upwelling in the northern Indian Ocean and downwelling in the southern Indian Ocean, and concluded that the dianeutral mixing plays a vital role in achieving water mass conversion and thermocline ventilation in the northern Indian Ocean.

In an annual mean situation, You and Tomczak [1993] noted that the movement of ICW toward the northern Indian Ocean was evident on the $\sigma_{\theta}=26.7$ isopycnal surface (see their Figures 9a, 13a and 15a), which is consistent with Warren et al. [1966, p. 842] who state that "northward-moving Subtropical Subsurface Water (namely ICW) appears to penetrate well north of the equator." You and Tomczak [1993] proposed a transition path of ICW: subduction in the South Indian Ocean at about $40^{\circ}-45^{\circ} \mathrm{S}$, advection with the subtropical gyre, and exit to the northern Indian Ocean as part of western boundary currents. The transformation of ICW to NICW is a very slow process, accompanied by a significant fall in oxygen values due to consumption by oxidation of organic matter and a corresponding increase of nutrient concentrations. The thermocline in the Bay of Bengal contains the oldest central water - NICW. The conclusion was drawn in favor of property distribution along the transition path of ICW on the isopycnal-mixing-dominated surface, $\sigma_{\theta}=26.7$. ICW and NICW have identical temperature and salinity but different oxygen and nutrient levels. You [1996] could trace this central water formation on the surface with mapped density ratio $R_{\rho}\left(R_{\rho}=\alpha \theta_{z} / \beta S_{z}\right)$, where $\alpha=-\rho^{-1} \partial \rho / \partial \theta$ is the appropriate thermal expansion coefficient, $\beta=\rho^{-1} \partial \rho / \partial S$ is the haline contraction coefficient, and $\theta z$, and $S z$ are vertical gradients of potential temperature and salinity. He found a steady increase of $\mathbf{R}_{\boldsymbol{\rho}}$ from 2 at the central water of subtropics to 20 near the Bay of Bengal along the path. The westward flow of AAMW across the Indian Ocean was also clearly shown in You and Tomczaks [1993] mixing model results. However, the reversed seasonal 
monsoons mentioned at the beginning are known to have a profound effect on the Indian Ocean circulation and water mass structure. The extent of this monsoonal effect on thermocline circulation and ventilation in their mixing model is not known, since You and Tomczak used only an annual mean data set.

Under the influence of two distinct monsoon regimes, the transition of ICW to the northern Indian Ocean may undergo strong seasonal changes. The throughflow of AAMW transported into the Agulhas Current should also be affected by the monsoon reversals, with stronger westward flow during the southwest monsoon in the upper thermocline, because South Equatorial Current reaches its maximum during the summer monsoon. During the winter monsoon the South Equatorial Current does not belong to the monsoon gyre [Wyrtki, 1973]. Wyrtki [1973] suggests a much stronger impact on the water masses below the thermocline by the southwest monsoon compared with the northeast monsoon. He pointed out that the depth of circulation is greatest during the southwest monsoon. This affects the movement of water masses far below the thermocline. The Somali Current formation causes a strong baroclinic adjustment of the structure which is especially pronounced in the upper $400 \mathrm{~m}$ and noticeable as deep as $1000 \mathrm{~m}$. Since the main thermocline water of the northern Indian Ocean is located in the 150 to $600 \mathrm{~m}$ depth range, well within the depth of monsoonal influence, the seasonal changes of main thermocline water masses in response to the monsoonal changes have to be considered. The thermocline circulation and ventilation studied in this paper are determined by examining water mass mixing among the four water mass of the system: ICW, NICW, AAMW, and RSW/PGW. Therefore the seasonal effect on these water masses, as defined through source water types, will be quantified. Afterward, calculation of the mixing ratios among those source water masses is carried out to account for a seasonal signal. In section 2 , two data sets, which represent two monsoon seasons, and the methods used in this paper are briefly described. The distribution of hydrographic parameters including pressure, potential temperature, salinity, dissolved oxygen, phosphate, and silicate on individual isopycnal surfaces for the two seasons is shown in section 3. The definition of the source water types for the two seasons is discussed in detail in section 4 . The results of the water mass mixing analyses for the two seasons are presented in section 5 . The summary and discussion in section 6 , based on a schematic of summer and winter thermocline circulation, conclude the paper.

\section{Data and Methods}

Because of the limited available data resources at that time, You and Tomczak [1993] used a single data set of historical hydrography, covering all seasons and years, to study the annual mean of thermocline circulation and ventilation in the Indian Ocean north of $40^{\circ} \mathrm{S}$. Since then there have been opportunities to access additional data from both historical and update cruises obtained for this ocean basin. The combined total data set has been synoptically divided into two seasons according to their measuring time, the southwest monsoon (May-October) and northeast monsoon (November-April) (hereinafter "summer" and "winter" refer to the northern hemisphere summer and winter seasons). As a result, there is reasonably good coverage for both seasons (see Figures $2 \mathrm{a}$ and $2 \mathrm{~b}$ ) on the uppermost isopycnal surface, $\sigma_{\theta}=25.7$, with a total of 1451 stations, for summer and 1651 for winter. This is reduced to 1299 for summer and 1468 for winter on the lowermost isopycnal surface, $\sigma_{\theta}=27$.1. The summer data are not distributed as well as the winter data (Figure 2).
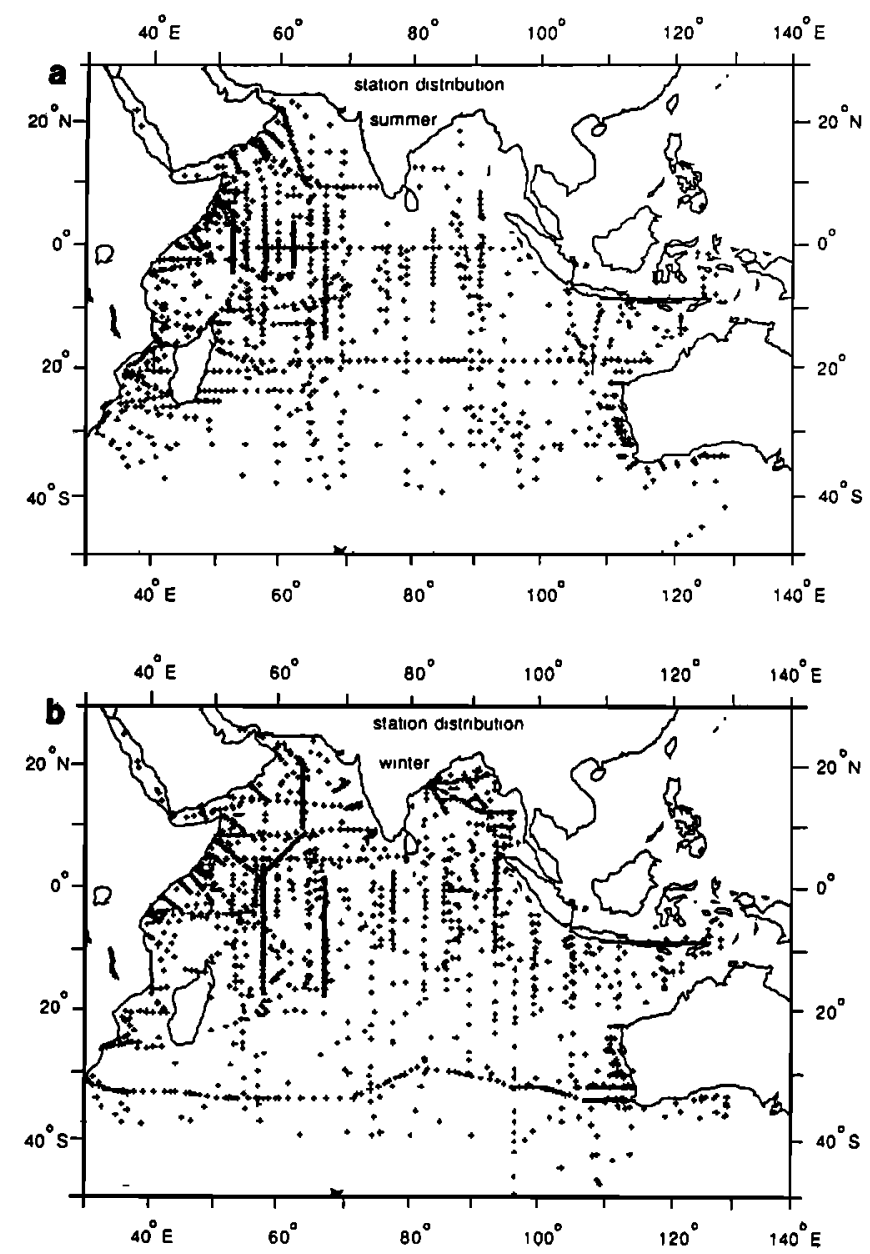

Figure 2. Distribution of hydrographic stations on the $\sigma_{\theta}=25.7$ isopycnal surface, during (a) the southwest monsoon (MayOctober) and (b) the northeast monsoon (November-April). Up to five parameters were measured at each station: temperature, salinity, oxygen, phosphate, and silicate.

These historical hydrographic data include (1) the National Oceanographic Data Center (NODC) data through Australian Oceanographic Data Center (AODC) and prepared from the University of Sydney [You and Tomczak, 1993], (2) the archived data available in the Center for Meteorology and Physical Oceanography, Massachusetts Institute of Technology (Y. You, an unpublished manuscript submitted to International WOCE News Letter, 1996), and (3) some recently completed cruises including Charles Darwin cruise 29 (CD29) data from the Woods Hole Oceanographic Institution [Toole and Warren, 1993], the Monsoon Arabian Sea Investigations (MASAI) data from the University of Maimi [Olson et al., 1993] and the French Indien Geochimie Ocean (INDIGO) data [Jamous et al., 1992]. These two seasonal data sets contain physical-chemical observations recorded at discrete depth levels including temperature $(T$, degree Celsius), salinity ( $\mathrm{S}$, practical salinity units (psu)), oxygen $\left(\mathrm{O}_{2}\right.$, milliliters per liter), phosphate $\left(\mathrm{PO}_{4}\right.$, microgram atom per liter), nitrate $\left(\mathrm{NO}_{3}\right.$, microgram atom per liter), and silicate, $\left(\mathrm{H}_{4} \mathrm{SiO}_{4}\right.$, microgram atom per liter). Since most stations do not contain nitrate observations, these data are not used. All the stations were then linearly interpolated for four selected isopycnal surfaces, $\sigma_{\theta}=25.7, \sigma_{\theta}=26.7, \sigma_{\theta}=26.9$ and $\sigma_{\theta}=27.1$, as used by You and Tomczak [1993]. 
A water mass is defined here as a body of water with a common formation history for all of its contained elements. The permanent thermocline contains several such water masses, which can penetrate one another as a result of mixing. As water masses are physical entities of finite volumn, they can be mathematically described by functional relationships between their characteristic properties and a set of standard deviations. A water type is defined as a point in parameter space; it is only a mathematical construct and does not occupy any volume in parameter space. The functional relationship of a water mass represented by its characteristic properties can then be described by an infinite set of water types, which are called source water types [Tomczak and Large, 1989]. In practice, if the functional relationship between all parameters of a water mass is linear, the water mass can then be described by a minimum of two source water types.

The variables used in this study are considered to be conservative (following You and Tomczak [1993]). This is a reasonable assumption if the analysis is restricted to mixing in the upper kilometer of the ocean and over horizontal distances of the order of hundreds of kilometers. On that scale, the effects of advection and turbulent diffusion clearly outweigh any biochemical effects [You and Tomczak, 1993]. However, the present analysis is concerned with circulation features on an oceanic scale where biochemical oxygen consumption and nutrient gain cannot be ignored. To cope with these effects in the frame work of OMP analysis, the virtual water mass NICW, introduced in section 1, is used to represent aged Indian Central Water. As was mentioned above, this "water mass" is defined only for the purpose of OMP analysis and not in the sense of our definition above. The main idea here is that when ICW transits to the northern Indian Ocean through advection and diffusion epipycnally (or epineutrally) or diapycnally (or dianeutrally) along the isopycnal surfaces (or neutral surfaces [see You, 1996]), ICW imprints its age. It is reflected in the change of oxygen and nutrient contents on its paths. In other words, ICW ages as its oxygen value decreases from its formation region to the Bay of Bengal. This is because ICW carries oxygen-rich water from the southern Indian Ocean to the northern Indian Ocean and its oxygen is consumed by oxidation of organic matter during its advection toward the Bay of Bengal. The same idea is applied in this paper. NICW is introduced to represent such aged ICW. It is defined in the Bay of Bengal and is distinguished from BBW, which is defined only for the surface low-salinity water by Mamayev [1975] and Emery and Meincke [1986] (see Figure 1).

You and Tomczak [1993] applied a mixing model which combines cluster analysis with OMP analysis to study the thermocline circulation and ventilation in the Indian Ocean. The method of OMP analysis, first proposed by Tomczak [1981] and further developed by Mackas et al. [1987], Tomczak and Large [1989], and You and Tomczak [1993], uses nutrients and dissolved oxygen, along with temperature and salinity, to derive a distribution of water masses that matches the observed distribution of properties in an objectively definable best fit. The technique was initially developed for a frontal mixing situation (mixing of two water masses) and later used for that purpose. You and Tomczak [1993] extended the method to an ocean-basin-wide mixing of the Indian Ocean thermocline. They used cluster analysis for an objective definition of water types as a precursor to OMP analysis. They applied the method on isopycnal surfaces which are more aligned with the probable mixing paths, giving meaningful results of thermocline circulation and ventilation. Following You and Tomczak [1993], "cluster analysis" is applied in this paper to determine the number of source water types required to adequately represent the water masses in the Indian Ocean thermocline and their parameter values. The method can generally be applied to find natural groupings, or clusters, in a data set with all parameters represented by one matrix. Hence the permanent thermocline can be classified into several groups, and with our oceanographic knowledge, the source water types can be identified by parameter combinations or points in parameter space (the cluster center) in the context of water mass analysis. By applying cluster analysis on a number of isopycnal surfaces in succession, it is possible to derive a series of source water types across the density range that spans the thermocline layer and approximates the parameter relationships of the unknown water masses to an anticipated accuracy. Readers are referred to You and Tomczak [1993] for the details of the application of cluster analysis.

The source water types determined as the cluster centers on individual isopycnal surfaces are then used to derive the "real" source water types through regression analysis in propertyproperty diagrams. The intersection points of the isopycnal surfaces and the fitted lines are then chosen as the "real" source water types for OMP analysis. Having thereby established the source water types and thus the water masses from cluster analysis, one can then calculate mixing proportions with OMP analysis. Here is the brief review of the method; it solves a linear system of mixing equations for each data point, in which all water masses are represented through water types [Tomczak and Large, 1989; You and Tomczak, 1993] and the linear system for any water sample can be written as

$$
G x_{g}-x_{v}=R
$$

where $G$ is a matrix containing the parameter values which define the source water types; $x_{\mathbf{v}}$ is a vector containing the parameter values for the sample (the observations); $\mathrm{x}_{\mathrm{g}}$ is a vector containing the relative contributions, or mixing ratios, of the source water types to the sample; and $\mathbf{R}$ is a vector containing residuals. The water mass conservation equation is expressed as

$$
\sum_{k=1}^{M} x_{g k}=1
$$

where $M$ is the total number of source water types. Equations (1) and (2) form a linear mixing model of all water masses. Solving equation (1) by minimizing the sum of the squared residuals leads to the determination of the minimum of

$$
\begin{aligned}
R^{\top} R & =\left(G x_{g}-x_{v}\right) W^{\top} W^{\top}\left(G x_{g}-x_{v}\right) \\
& =\sum_{j=1}^{m} W_{j}^{2}\left(\sum_{i=1}^{n} G_{j i} x_{g i}-x_{v j}\right)^{2},
\end{aligned}
$$

where $m$ is the number of parameters, $n$ is the total number of stations, and $W$ represents the weight attributed to the various parameters, reflecting differences in measurement accuracy, degree of conservativeness, and other processes which may render some parameters less reliable than others. These weights are derived from

$$
W_{j}=\sigma_{j}^{2} / \delta_{j \max }
$$

where $\sigma_{j}$ is the standard deviation of parameter $j$ over the entire 
data set (a measure for the ability of parameter $j$ to resolve differences in water mass content), defined as

$$
\sigma_{j}=\sqrt{\frac{1}{n} \sum_{i=1}^{n}\left(G_{j i}-G_{j}\right)^{2}}
$$

and $\delta_{j \mathrm{max}}$ is the largest variations for the water masses. $G_{j}$ is the mean of $G_{j 1}$ given by

$$
G_{j}=\frac{1}{n} \sum_{i=1}^{n} G_{j i} \text {. }
$$

Two conservative parameters, temperature (beneath the mixed layer) and salinity, usually attain the largest weight. This largest weight is also allocated to the mass conservation equation (2), since the method of weight calculation described above is not applicable to mass conservation.

As was mentioned above, five parameters were found to provide useful information for the present study. This restricts the number of source water types that can be handled by OMP analysis to a maximum of six, and we must ask whether six water types are sufficient to represent all water masses in the region. The earlier discussion established the presence of three source water mass systems, ICW, AAMW, and RSW/PGW, in the main thermocline of the Indian Ocean. Later, an additional virtual water mass, NICW, was introduced to represent the aged ICW. This is a total of four water masses, but OMP analysis can handle only three in this particular case. However, as was mentioned above, RSW/PGW provide a relatively small contribution to the thermocline circulation and ventilation, between about $30 \%$ annually to the Arabian Sea Water estimated by You and Tomczak [1993] and about 10\% estimated by Olson et al. [1993] through CFC data analysis. Therefore, with the limitation of the method to handle the number of source water types, RSW/PGW is excluded from OMP analysis, although by parallel calculation in the western Indian Ocean upper thermocline its relative contribution could still be estimated by excluding AAMW. This is because in the uppermost thermocline, AAMW shows jet-like flow apparent in the eastern Indian Ocean, while relatively small amount of its water reaches the western Indian Ocean. Consequently, for the western Indian Ocean the contribution by RSW/PGW can be approximated through the calculation of mixing among ICW, NICW and RSW/PGW. Readers are referred to You and Tomczak [1993] for this particular approach. With five parameters and six source water types, OMP analysis does not degenerate into a uniquely determined system of equations [Tomczak, 1981] because the solutions, which are subject to the nonnegativity' constraint, have to be determined through residual minimization.

\section{Seasonal Variations of Parameter Distribution on the Isopycnal Surfaces}

Four isopycnal surfaces $\left(\sigma_{\theta}=25.7,26.7,26.9\right.$ and 27.1) were mapped to span the main thermocline from about 150 to $800 \mathrm{~m}$ on average. Each pair of surfaces is about $150-200 \mathrm{~m}$ apart. The distance between the same set of surfaces in the southern Indian

Figure 3. Distribution of hydrographic properties on the $\sigma_{\theta}=25.7$ isopycnal surface, for (left) the summer monsoon and (right) the winter monsoon: (a) pressure ( $\mathrm{P}, \mathrm{dbar})$, (b) potential temperature $\left(\theta\right.$, degree Celsius), (c) salinity $(S, \mathrm{psu}),(\mathrm{d})$ oxygen $\left(\mathrm{O}_{2}\right.$, milliliters per liter), (e) phosphate $\left(\mathrm{PO}_{4}\right.$, microgram atom per liter), and (f) silicate $\left(\mathrm{H}_{4} \mathrm{SiO}_{4}\right.$, microgram atom per liter).
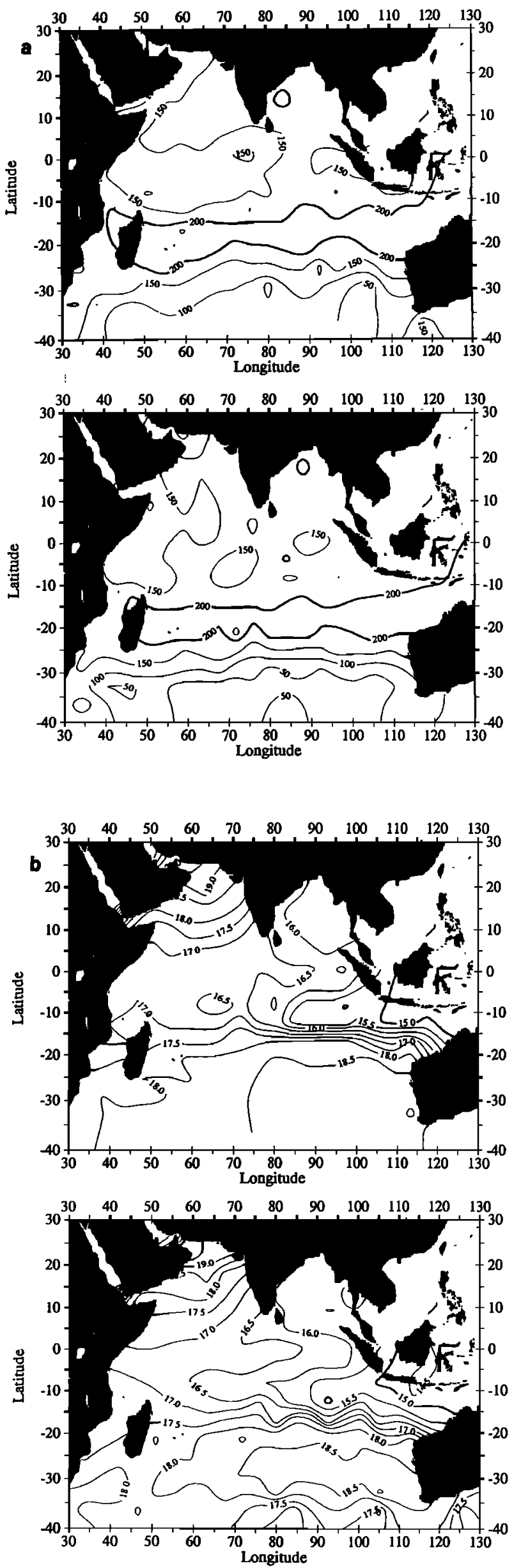

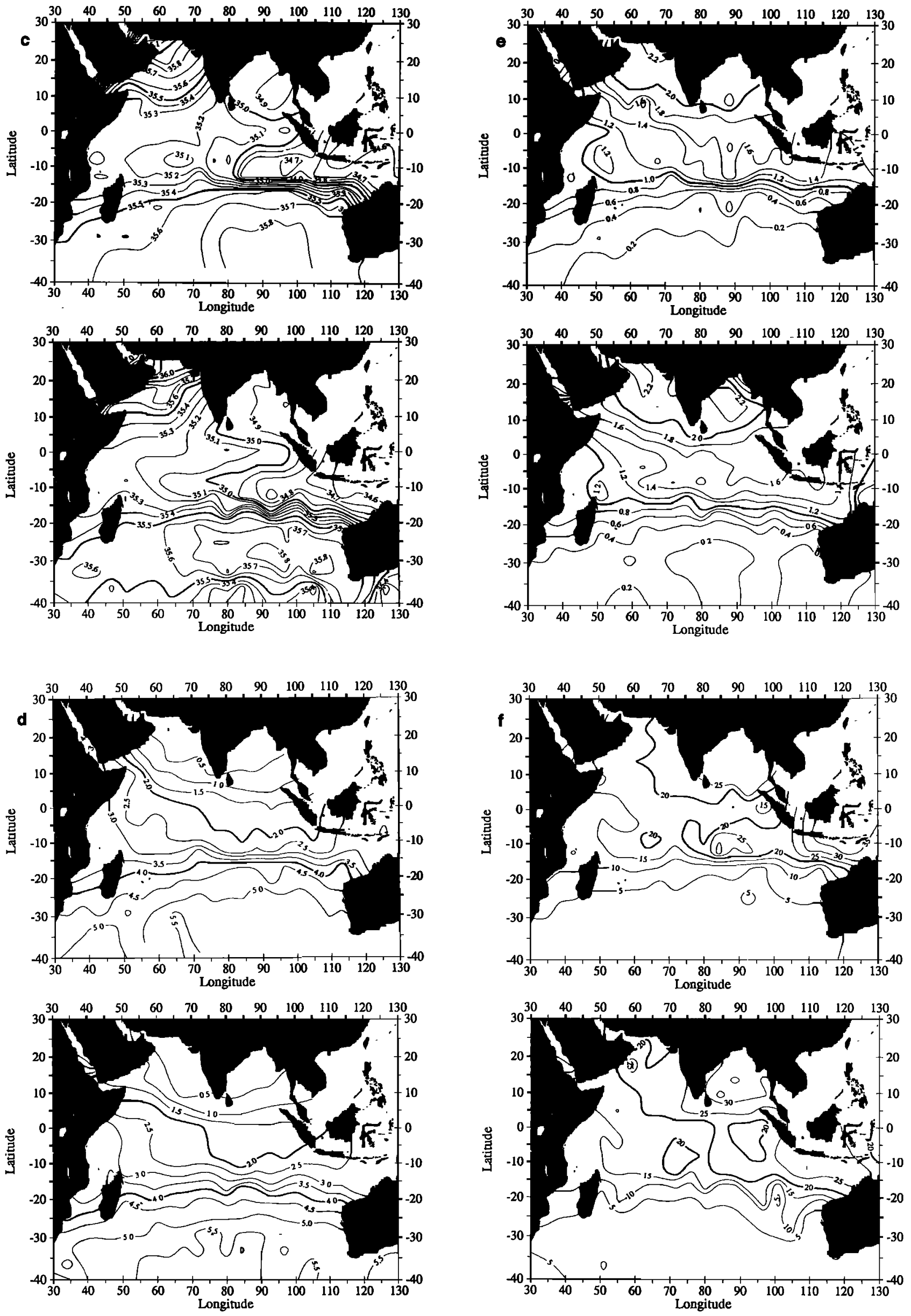

Figure 3. (continued) 

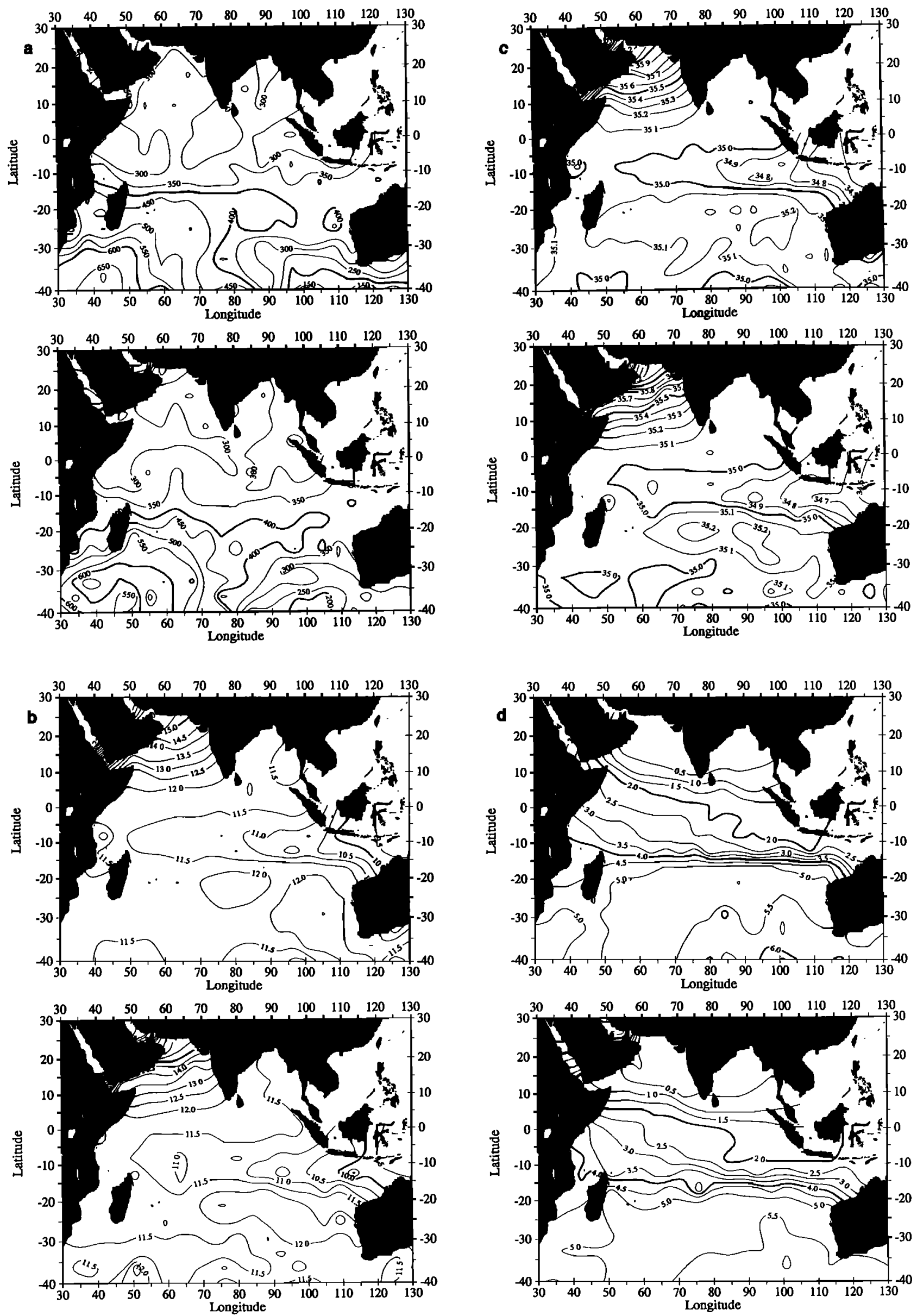

Figure 4. Same as Figure 3 but on the $\sigma_{\theta}=26.7$ isopycnal surface. 

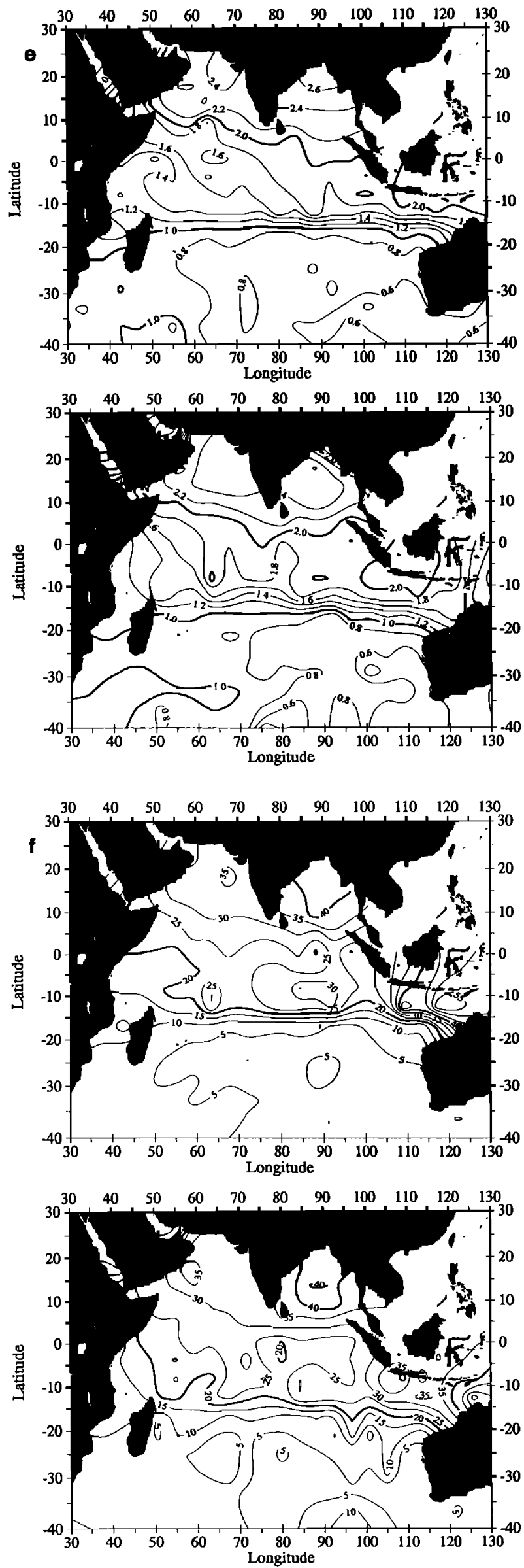

Figure 4. (continued)
Ocean is about $50 \mathrm{~m}$ wider than in the northern Indian Ocean. Pressure, potential temperature, salinity, oxygen, phosphate, and silicate for the summer monsoon (the left panels) are directly compared with the same parameters of the winter monsoon (the right panels) in Figures 3-6. Seasonal differences in all parameters are seen clearly. The uppermost isopycnal surface, $\sigma_{\vartheta}=25.7$, lies in the upper thermocline and therefore experiences the greatest seasonal change. In Figure 3a during both summer and winter monsoons there is a distinct high-pressure band between about $10^{\circ} \mathrm{S}$ and $25^{\circ} \mathrm{S}$, east-west tilting with five latitudinal degrees more to the south in the western Indian Ocean. This high-pressure band is slightly wider and extends more westward to the eastern African coast during the summer monsoon (Figure 3a, left panel). Ocean thermocline deepening in this latitudinal band suggests the throughflow path of AAMW, which is indicated by lowtemperature, low-salinity water flowing in from the Indonesian seas, seen as the tongues in Figures $3 b$ and $3 c$. North of the highpressure band in the equatorial and northern Indian Ocean for the summer in Figure 3a, there is a large low-pressure tongue extending from the Somali coast to the northeast Indian Ocean accompanied by relatively uniform temperature and salinity distributions (left panels of Figures $3 b$ and $3 c$ ).

A significant pressure difference between the two seasons is seen in the subtropical ocean south of $30^{\circ} \mathrm{S}$ (Figure 3a) where the thermocline shallows between 50 and $100 \mathrm{~m}$ during the winter monsoon. The right panel of Figure $3 \mathrm{a}$ reflects the effect of northward low-temperature, low-salinity water from the Southern Ocean as seen in the right panels of Figures $3 \mathrm{~b}$ and $3 \mathrm{c}$ south of $32^{\circ} \mathrm{S}$. Seasonal signals are apparent in the temperature and salinity fields of Figures $3 b$ and $3 c$, indicative of the signals for the Somali Current. The $17.0^{\circ} \mathrm{C}$ isotherm and 35.3 isohaline clearly show a northward extension along the Somali coast during the southwest monsoon, with a return southward during the northeast monsoon. These contour lines migrate about 5 to 8 latitudinal degrees between the two seasons.

The seasonal differences of temperature and salinity are also apparent in the eastern Indian equatorial region, where same contours propagate more eastward in the summer than in the winter. Note the $16.5^{\circ} \mathrm{C}$ isotherms and 35.0 isohalines at the equator in Figures $3 \mathrm{~b}$ and $3 \mathrm{c}$. A slightly stronger summer signal for AAMW is more obvious in the salinity contours in the left panel of Figure $3 \mathrm{c}$ where a low-salinity tongue extends more westward to the eastern African coast (compare the 35.2 isohaline). In fact, a stronger southwest monsoon, compared to the northeast monsoon, stands out by the more uniformly distributed temperature and salinity fields in the subtropical and Somali Current regions.

The temperature and salinity contours are different in the subtropical ocean during the northeast monsoon in the right panels of Figures $3 \mathrm{~b}$ and $3 \mathrm{c}$ and are significantly affected by the austral summer season. The low-temperature, low-salinity water south of $32^{\circ} \mathrm{S}$ indicates most likely Southern Ocean surface water moving to north, initiated by ice melting and precipitation during austral summer. Colborn [1975] suggested that during the austral summer, a weaker thermocline formation occurs near the Subtropical Convergence Zone, while during the northern hemisphere summer the surface water could be mixed to a relatively great depth. It is quite clear from the right panels of Figures $3 \mathrm{~b}$ and $3 \mathrm{c}$ that the weaker thermocline formation is caused by invasion of the cooler and fresher water from the south. Sverdrup et al. [1942, pp. 695 ] were probably the first to note the impact of seasonal change on ocean currents in the southern Indian Ocean, stating that "between South Africa and Australia the current is directed in general from west to east. In the southern 

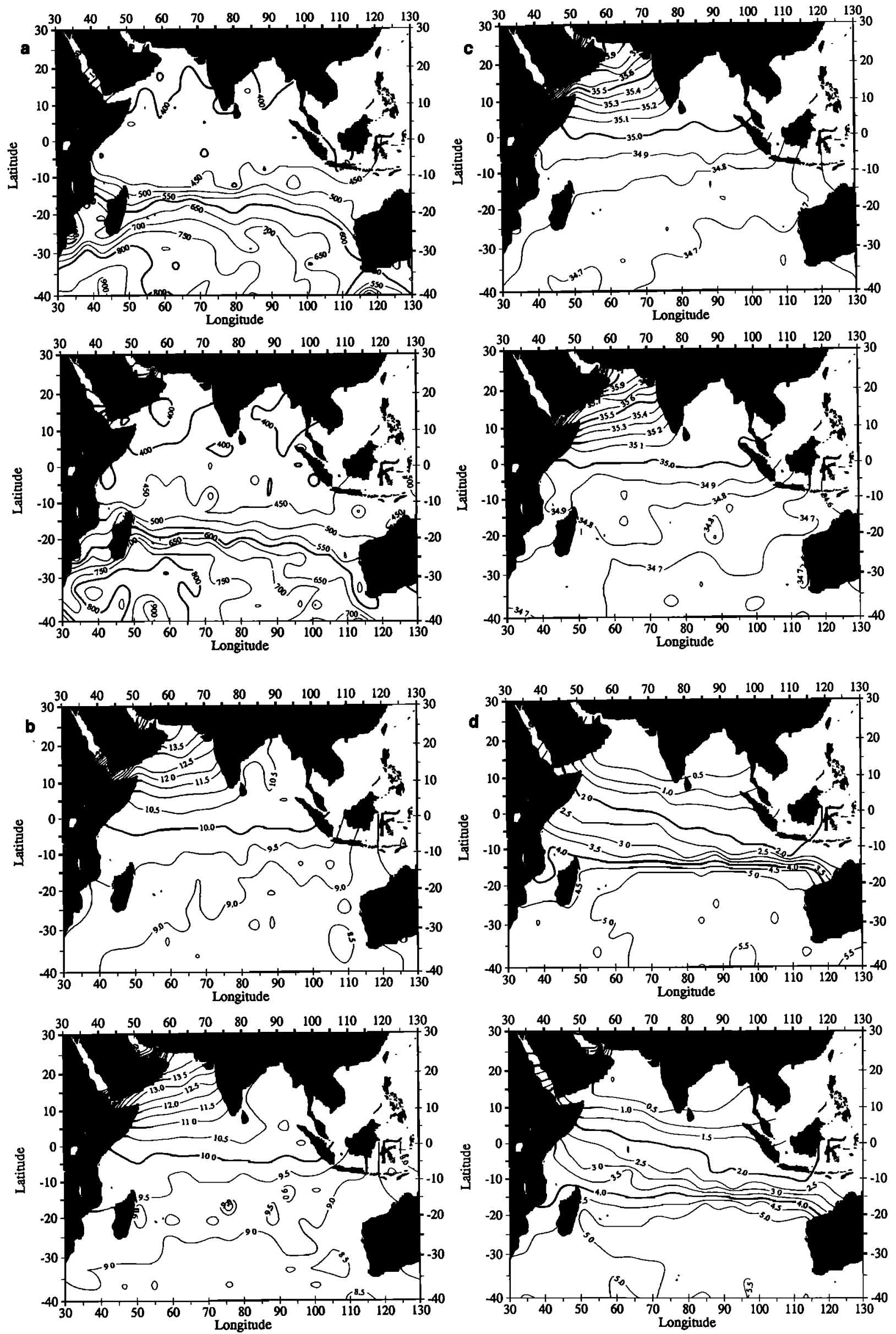

Figure 5. Same as Figure 3 but on the $\sigma_{\theta}=26.9$ isopycnal surface 

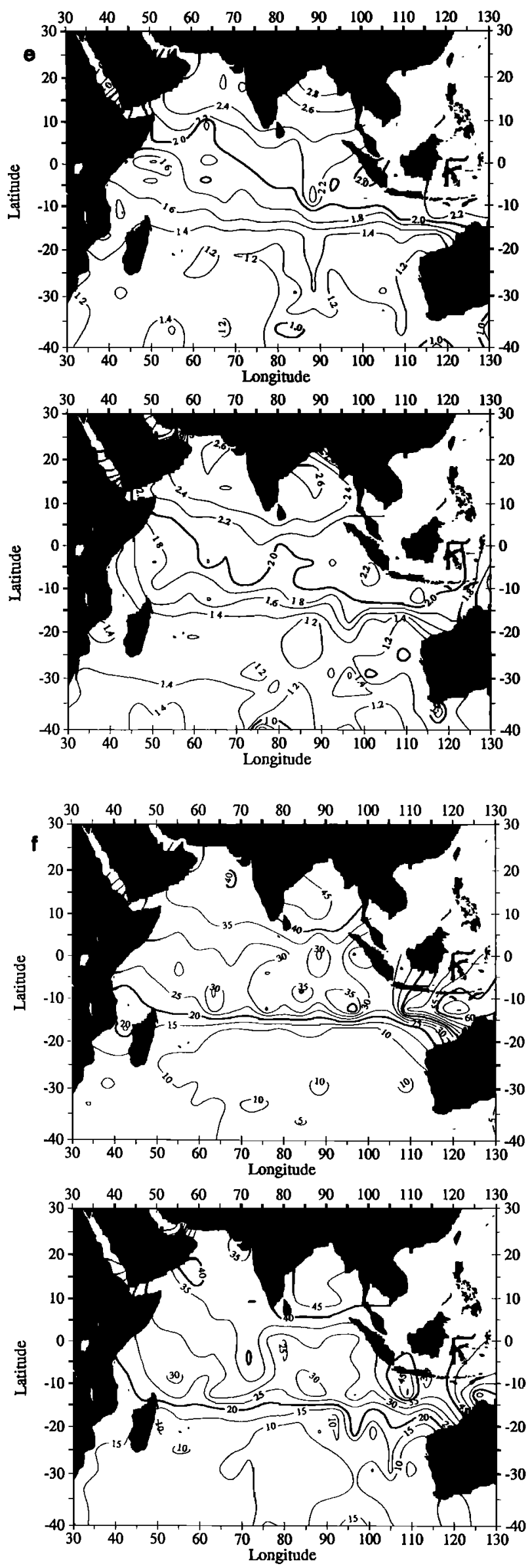

Figure 5. (continued) summer the current bends north before reaching the Australia continent." These early studies suggest that the Subtropical Convergence Zone probably migrates northward for some degrees during the austral summer and so does the subtropical gyre, at least in its southern bounds. The right panels of Figures $3 \mathrm{~b}$ and $3 \mathrm{c}$ suggest such a seasonal shift probably for about 5 latitude degrees. Seasonal changes certainly complicate the gyre dynamics as well. When Wyrtki [1973, pp. 26 ] was inspecting the dynamic topography for two seasons, he found that "the subtropical gyre of the southern Indian Ocean is developed somewhat differently from the corresponding gyres in the other oceans." These suggest that one should be careful while calculating geostrophic flows. Seasonal changes have to be considered even in the southern Indian Ocean. The seasonal signal is apparent in the Mozambique Channel and east of Madagascar. In the Mozambique Channel the 35.3-psu contour line in Figure 3c extends farther south during the summer. A striking seasonal difference is found east of Madagascar. Contour lines extend southward during the summer but reverse to the north during the winter (note the northward stretching of the 35.3 isohaline to north of Madagascar in the right panel). This seasonal reversal is also revealed in other property distributions and on the lower isopycnal surfaces. As we know, these seasonal changes have important implications for the circulation in the southwest Indian Ocean, particularly in respect to the Agulhas Current.

Large seasonal signals are also reflected in oxygen and nutrient fields. Like temperature and salinity, one can see in Figures 3d, $3 \mathrm{e}$, and $3 \mathrm{f}$ that the contour lines of oxygen $(2.5 \mathrm{~mL} / \mathrm{L})$, phosphate $(1.4 \mu \mathrm{g}-$ atom $/ \mathrm{L})$ and silicate $(20 \mu \mathrm{g}$ - atom $/ \mathrm{L})$, apparently extend more northward along the Somali coast during the southwest monsoon (left panels) than during the northeast monsoon (right panels). It is noted that oxygen and phosphate do not show clear signals for AAMW because ICW is too strong, while silicate marks the summer extension of AAMW clearly. The left panel of Figure $3 \mathrm{f}$ indicates a relatively low silicate band extending from the Somali Current region to the eastern Indian equatorial region, separating the higher-silicate water in the Bay of Bengal from that of the AAMW tongue. This clearly suggests that the high-silicate water in the Bay of Bengal is not from the same source as AAMW. The separation is not so obvious during the winter (Figure 3f, right panel), implying that the communication between AAMW and the water in the Bay of Bengal only might occur during the northeast monsoon.

You and Tomczak [1993] found that the $\sigma_{\theta}=26.7$ isopycnal surface is more characterized by isopycnal mixing. They implied that the ventilation water in the northern Indian Ocean originated from the Southern Ocean and is most likely advected along this surface. This isopycnal surface lies at about the $400 \mathrm{~m}$ depth level (Figure 4a) and is characterized by almost the same temperature and salinity values for both the summer and winter monsoons (Figures $4 \mathrm{~b}$ and $4 \mathrm{c}$ ) between the formation region of ICW at $40^{\circ} \mathrm{S}$ to the subtropical gyre, and the western boundary region to the Bay of Bengal. The northward extension of contour lines in temperature $\left(12.5^{\circ} \mathrm{C}\right)$ and salinity $(35.2 \mathrm{psu})$ fields during the southwest monsoon is seen clearly along the Somali coast in the left panels of Figures $4 \mathrm{~b}$ and $4 \mathrm{c}$. As seen above, the throughflow water of AAMW is indicated by the low-temperature and lowsalinity water tongues in Figures $4 \mathrm{~b}$ and $4 \mathrm{c}$. A northward summer migration of about 5 degrees in the contour lines of oxygen and nutrients is seen clearly in the left panels of Figures $4 \mathrm{~d}, 4 \mathrm{e}$, and $4 \mathrm{f}$ at the Somali Current region. The high-silicate tongue in the left panel of Figure $4 f$, associated with AAMW and separated by a relative silicate minimum to the north, extends farther westward 

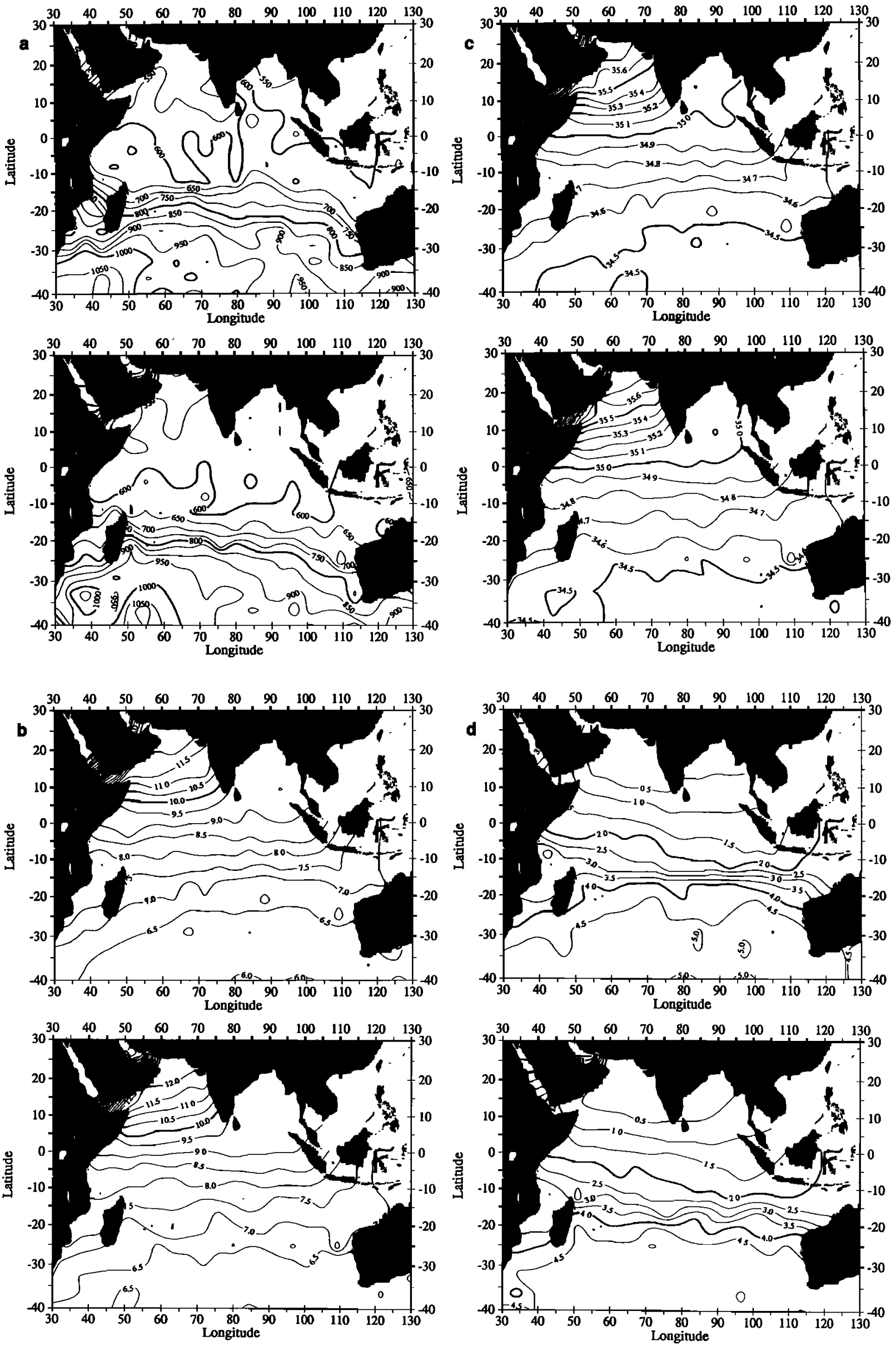

Figure 6. Same as Figure 3 but on the $\sigma_{\theta}=27.1$ isopycnal surface. 

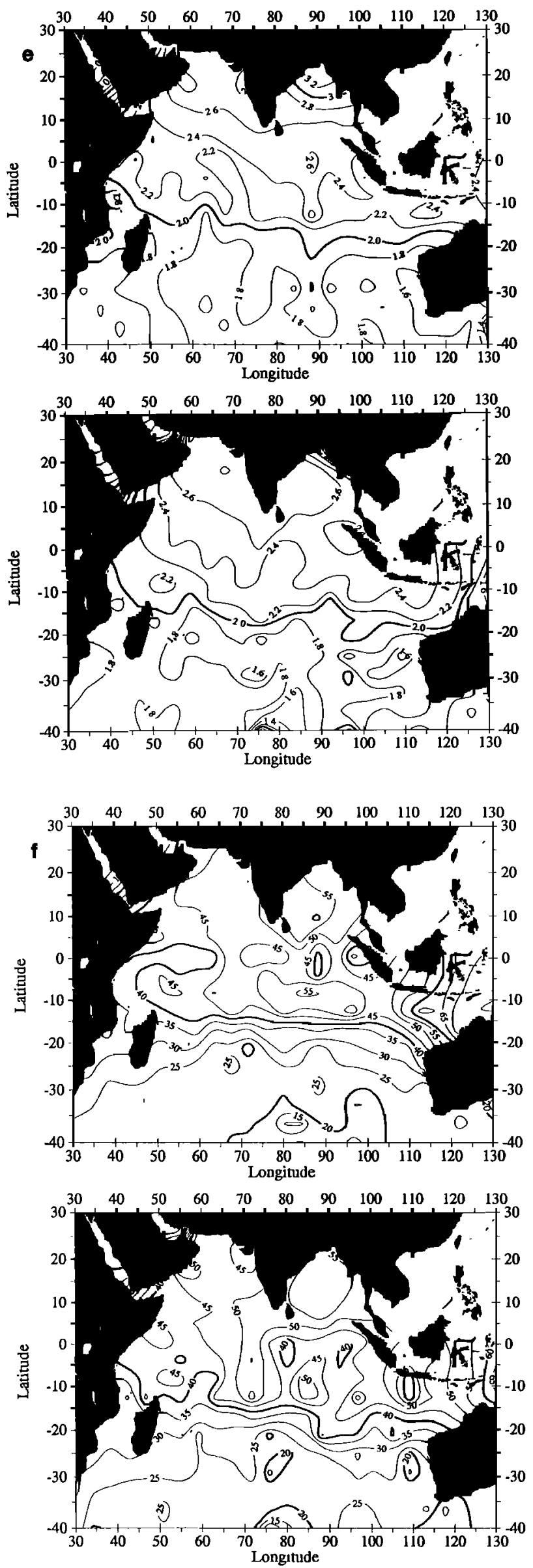

Figure 6. (continued) than in the winter (right panel), suggesting a relatively larger summer signal.

Though one might argue that the proposed transition path of ICW by You and Toinczak [1993] is reasonably supported by the temperature and salinity fields as seen in Figures $4 b$ and $4 c$, this path is not obvious in the oxygen and nutrient fields. This has already been described before in a concept of water mass aging. Oxygen in ICW starts to decrease after it last comes in contact with the atmosphere in the southern Indian Ocean and advects to the northern Indian Ocean because of the biochemical oxygen consumption and corresponding nutrient gain during the remineralization processes. Colborn [1975] suggested the usefulness of oxygen in the Indian Ocean as an indicator for the relative age of $I C W$. Because there is a strong hydrological front at $15^{\circ} \mathrm{S}$ east of $50^{\circ} \mathrm{E}$ formed by the throughflow (AAMW), the westem boundary (west of $50^{\circ} \mathrm{E}$ ) becomes only one possible path for ICW transiting to the north. You and Tomczak [1993] proposed that northward transition of ICW occurs in the western boundary current and that the Bay of Bengal contains the oldest ICW. This is further supported by the property distributions on the $\sigma_{\theta}=26.7$ isopycnal surface in Figure 4. Except for the afore mentioned temperature and salinity distributions and the stronger northward transition of oxygen and nutrients during the summer in the Somali Current region, one notes that there is a rather clear transition path of ICW to the Bay of Bengal east of Sri Lanka. The left panels of Figures $4 \mathrm{~d}, 4 \mathrm{e}$ and $4 \mathrm{f}$ show a consistent northward extension of oxygen $(1.5,1.0$ and $0.5 \mathrm{~mL} / \mathrm{L})$, phosphate (2.0 and $2.2 \mu \mathrm{g}$ - atom/L) and silicate (30 and $35 \mu \mathrm{g}$ atom $/ \mathrm{L}$ ) contour lines east of Sri Lanka during the southwest monsoon that is not so evident during the northeast monsoon in the right panels. This will be further supported by the water mass mixing ratio distribution discussed later, in section 5 . In contrast to the southward flow east of Madagascar during the summer (left panels of Figures 4d to 4f), northward reversal during the winter is again seen clearly in the oxygen ( 5.0 and $4.5 \mathrm{~mL} / \mathrm{L})$, phosphate ( 1.0 and $1.2 \mu \mathrm{g}-$ atom/L) and silicate $(10$ and $15 \mu \mathrm{g}-$ atom/L) contour lines in the right panels of Figures $4 d, 4 e$, and $4 f$. This situation consistently occurs even in the deeper surfaces, for example, the right panels of Figures $5 \mathrm{c}(\mathrm{S}=34.8 \mathrm{psu}), 5 \mathrm{~d}\left(\mathrm{O}_{2}=5.0\right.$ $\mathrm{mL} / \mathrm{L}), 5 \mathrm{f}\left(\mathrm{H}_{4} \mathrm{SiO}=15 \mu \mathrm{g}-\right.$ atom $\left./ \mathrm{L}\right), 6 \mathrm{~b}\left(T=7.0^{\circ} \mathrm{C}\right), 6 \mathrm{c}(S=34.6$ $\mathrm{psu}), 6 \mathrm{~d}\left(\mathrm{O}_{2}=4.5\right.$ and $\left.4.0 \mathrm{~mL} / \mathrm{L}\right)$, and $6 \mathrm{f}\left(\mathrm{H}_{4} \mathrm{SiO}_{4}=30,35\right.$ and 40 $\mu \mathrm{g}-$ atom/L).

Wyrtki [1973] suggested that the pronounced seasonal variations occurred primarily only in the upper $400 \mathrm{~m}$. The $\sigma_{\theta}=26.7$ isopycnal surface discussed above is just located at this level. At greater densities the seasonal effect on property fields becomes weaker. Figure 5 shows the $\sigma_{\theta}=26.9$ isopycnal surface, which has an average depth of about $600 \mathrm{~m}$ for both seasons in Figure 5a. Seasonal signals can still be clearly identified along the Somali coast in the summer temperature $\left(11.5^{\circ} \mathrm{C}\right)$ and salinity $(35.3 \mathrm{psu})$ fields in the left panels of Figures $5 \mathrm{~b}$ and $5 \mathrm{c}$, where at least 2 degrees of latitudinal shift are evident. In contrast with the upper two isopycnal surfaces, the temperature and salinity fields at $\sigma_{\theta}=26.9$ do not show any structure for AAMW during the two seasons. This suggests AAMW to be significantly weaker on this level. However, AAMW can still be identified in the silicate field in Figure 5f, where AAMW is characterized by slightly higher silicate and distinguished from the high silicate of NICW by relatively lower silicate in between. The seasonal signal does not disappear even at the deepest $\sigma_{\theta}=27.1$ isopycnal surface in Figure 6. The difference of seasonal signal can still be well identified, for example, the summer temperature $\left(11.0^{\circ} \mathrm{C}\right)$, salinity $(35.4 \mathrm{psu})$ and oxygen $(1.0 \mathrm{~mL} / \mathrm{L})$ in the left panels of Figures $6 \mathrm{~b}, 6 \mathrm{c}$, and $6 \mathrm{~d}$ in contrast to the right panels during the winter. 


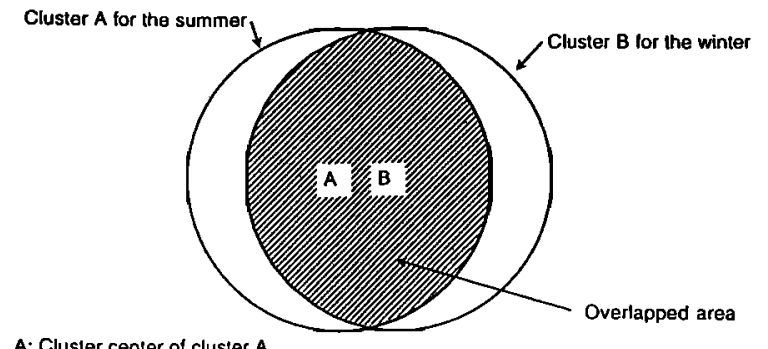

B Cluster center of cluster $B$

(a)

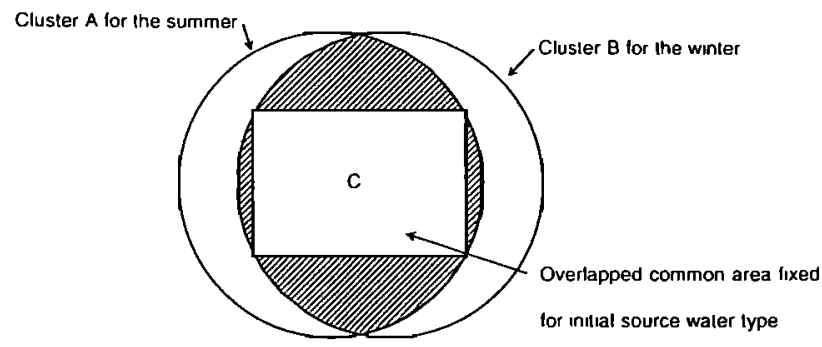

C Cluster center for both cluster $A$ and $B$

delinitions of the two seasons

(b)

Figure 7. Illustration of how a fixed sampling area is taken in the overlapped region of two clusters from two different seasons for accurate determination of seasonal signals in the initial source water types: (a) two cluster centers of two seasons (A and B), and (b) one cluster center $(C)$ for two seasons.

\section{Definition of Source Water Types and the Mixing Model}

As mentioned above, the source water types determined as the cluster centers on individual isopycnal surfaces were used as initial guesses for the final determination of the "real" source water types. The data in the respective regions were used to determine the cluster centers (i.e., points in parameter space which give the smallest sum of the distances to all other points in their respective cluster). However, since we are studying the seasonal variations of thermocline circulation and ventilation, an accurate determination of the initial source water types is crucial to the mixing model. Although the respective regional shifting of the clusters on an isopycnal surface (presumably caused by seasonal changes) cannot affect the definition of the same source water type very much, it can change the location of cluster centers to some degree in different seasons. Therefore seasonal signals derived from uncommon cluster centers can no longer be compared. To derive a more accurate seasonal signal in initial source water types, a fixed area was taken in the overlapping two clusters of the two seasons for initial source water type definitions of both the summer monsoon and the winter monsoon. This is represented schematically in Figure 7 . In the case of Figure 7a, since two clusters cover different areas in two different seasons, their centers are then not located in the same place, $A$ and $B$. This problem can be solved in the case of Figure $7 \mathrm{~b}$ by taking a fixed area in the overlapping region of two clusters of two seasons, so that two clusters have a common cluster center $\mathrm{C}$. The difference between any parameter measured at $\mathrm{C}$ during the two seasons is then considered to be the true seasonal signal for the source water types, and these seasonal signals can be compared to each other.
The initial source water types derived through cluster analysis on each isopycnal surface are then plotted in property-property diagrams: temperature against salinity, temperature against oxygen, and temperature against nutrients, as shown in Figure 8. We note that cluster analysis presents a simplified water mass structure. The calculation was carried out for all four isopycnal surfaces during the two seasons. Consequently, four cluster centers, or initial source water types, were obtained for each source water mass. Figure 8 shows that in all cases except for one (the $\mathrm{\theta}-\mathrm{H}_{4} \mathrm{SiO}_{4}$ relationship for ICW in Figure 8d), the propertyproperty relationships defined by the initial source water types are close to linear. Based on these already nearly linear initial source water types, the closest linear representations are determined through regression analysis, which are shown as the straight lines in Figure 8. For a comparison between the two seasons, results are shown in the left panels for the summer monsoon and the right panels for the winter monsoon. The four isopycnal surfaces applied have been indicated in the $\theta-S$ diagram in Figure 8a. A glimpse at these mapped source water types contains already informations about seasonal signals. For example, the largest seasonal variation is found in RSW/PGW water types (see Figure 8). The final "real" source water types for mixing model were obtained as intersections of regression lines and the specified isopycnal surfaces. They are indicated as the open circles in Figure 8.

The procedure also yields a variance for each water mass used to determine $\delta_{\text {jax }}$ in equation (4). In fact, the standard deviation was calculated for each parameter of each source water mass in order to calculate the weights. Because the silicate value for ICW more than doubles from the surface $\sigma_{\theta}=26.9$ to $\sigma_{\theta}=27.1$ and therefore the $\boldsymbol{\theta}-\mathrm{H}_{4} \mathrm{SiO}_{4}$ relationship of ICW cannot be represented by a single linear relationship, the procedure was applied separately to the density surfaces above and below the $\sigma_{\theta}=26.9$ density surface. The "real" source water types needed for OMP analysis were taken from the intersection points of regression lines and isopycnal surfaces as the values found on the highest $\left(\sigma_{\theta}=25.7\right)$ and lowest $\left(\sigma_{\theta}=27.1\right)$ density surfaces and on the density surface $\left(\sigma_{\theta}=26.9\right)$ at the break point of the $\theta-\mathrm{H}_{4} \mathrm{SiO}_{4}$ relationship of ICW. They are tabulated, together with weights derived from the data and water mass variances, in Table 2 and Table 3 for the two monsoon seasons. The seasonal differences for each source water type can be examined by comparing the two tables. Of all the source water types, RSW/PGW has the strongest seasonal variation, NICW has the next strongest seasonal variation, and ICW has the weakest seasonal variation at the source region. This is because the ICW source region is not under mosoonal effect. Since we have only six linear equations in (1) and (2), corresponding to five parameters and one water mass conservation equation, our water mass mixing model can handle a maximum of only six source water types. With a minimum of two source water types, required to define one source water mass, mixing among the six source water types on the highest and lowest density surfaces for ICW, NICW, and AAMW constitutes the mixing model. It is used to derive mixing ratios as discussed in the following section. Meanwhile, the relative contribution of RSW/PGW will also be estimated on the uppermost isopycnal surface in the model and as a residual on the other surfaces.

\section{Results}

\section{1. Isopycnal Surfaces}

With the limitation of only six available equations, the mixing model comprises three water masses. It outputs mixing ratios for each water mass (i.e., the sum of the contributions from its two 

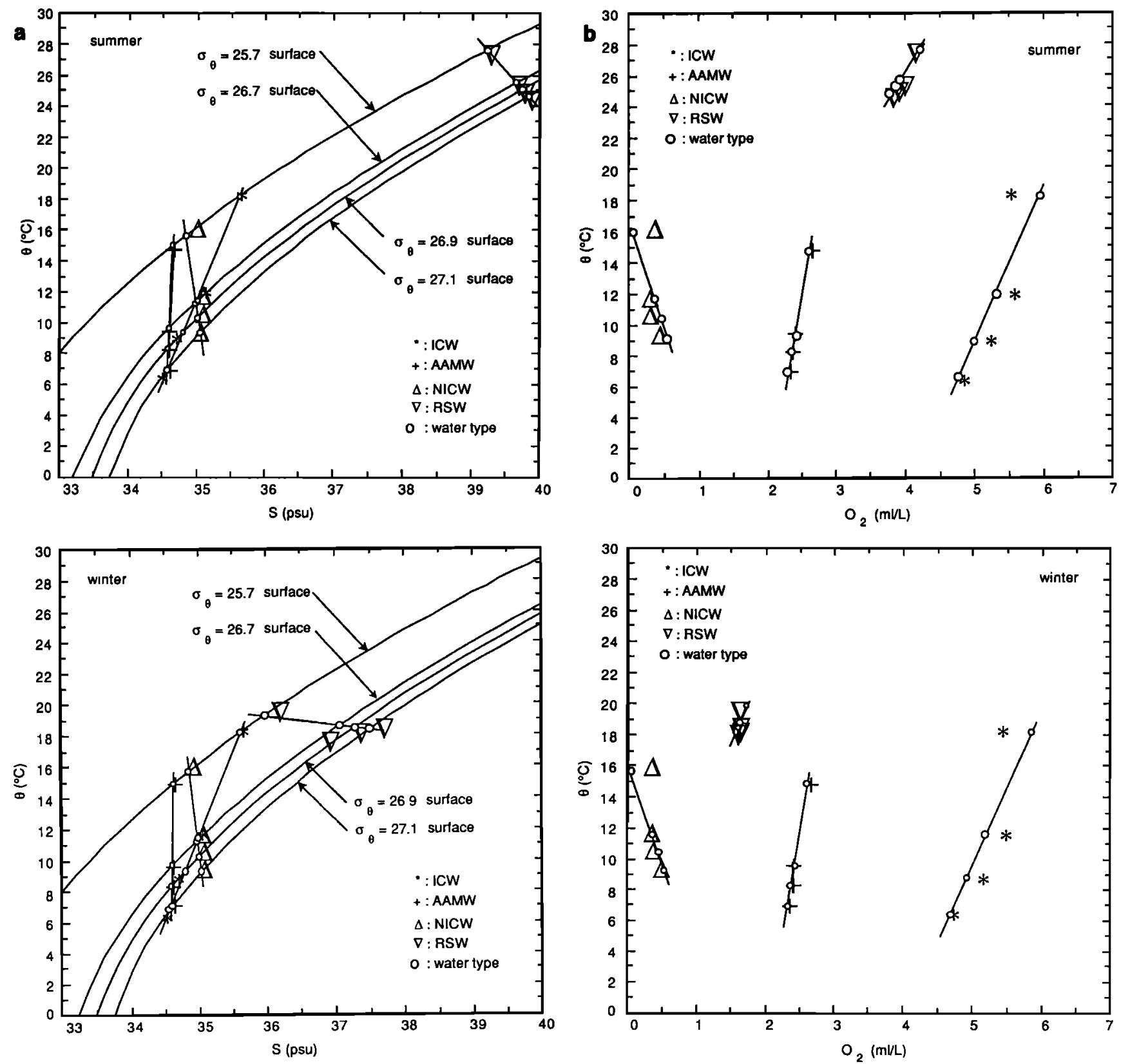

Figure 8. The definition of source water types in property-property plots as derived from cluster analysis, for (left) the summer monsoon and (right) the winter monsoon: (a) potential temperature-salinity diagrams, (b) potential temperature-oxygen diagrams, (c) potential temperature-phosphate diagrams, and (d) potential temperature-silicate diagrams.

source water types); the sum of all mixing ratios for all three water masses adds to $100 \%$ plus a residual. Figures $9-12$ show the contributions of the source water masses to the thermocline water circulation and ventilation derived from the mixing model for the summer monsoon (left panels), in contrast to the winter monsoon (right panels). Figure 9 shows the mixing ratios on the $\sigma_{\theta}=25.7$ isopycnal surface, which experiences the largest seasonal change among the four isopycnal surfaces. Three water masses, ICW, NICW, and AAMW, are included in the mixing model, and their mixing proportions are shown in Figures 9a, 9b, and 9c for both the southwest and the northeast monsoons. The relative contribution of RSW/PGW is also estimated on this isopycnal surface (Figure 9d) by including ICW, NICW, and RSW/PGW but excluding AAMW in the western Indian Ocean for the upper thermocline from the mixing model [You and Tomczak, 1993].
The property distributions were analyzed in section 3 . They showed large seasonal signals on this uppermost isopycnal surface. Figure 9 contains further evidence on the mixing ratio distributions of the source water masses. Percentage contour lines for ICW during the southwest monsoon in the left panel of Figure 9a clearly show northward extension along the Somali coast (see the $60 \%$ contour line), indicative of more ICW in the Somali Current flowing to the north. At least $10 \%$ more ICW is carried to the eastern equatorial Indian region during the summer than during the winter (compare left and right panels of Figure 9a; also see the 20 and $30 \%$ contour lines). In contrast, there is no northward stretching of the percentage contour lines seen in the Somali Current region during the northeast monsoon. Instead the right panel of Figure 9a shows a southward extension. The northward excursion of 20 and $10 \%$ ICW contour lines east of Sri 

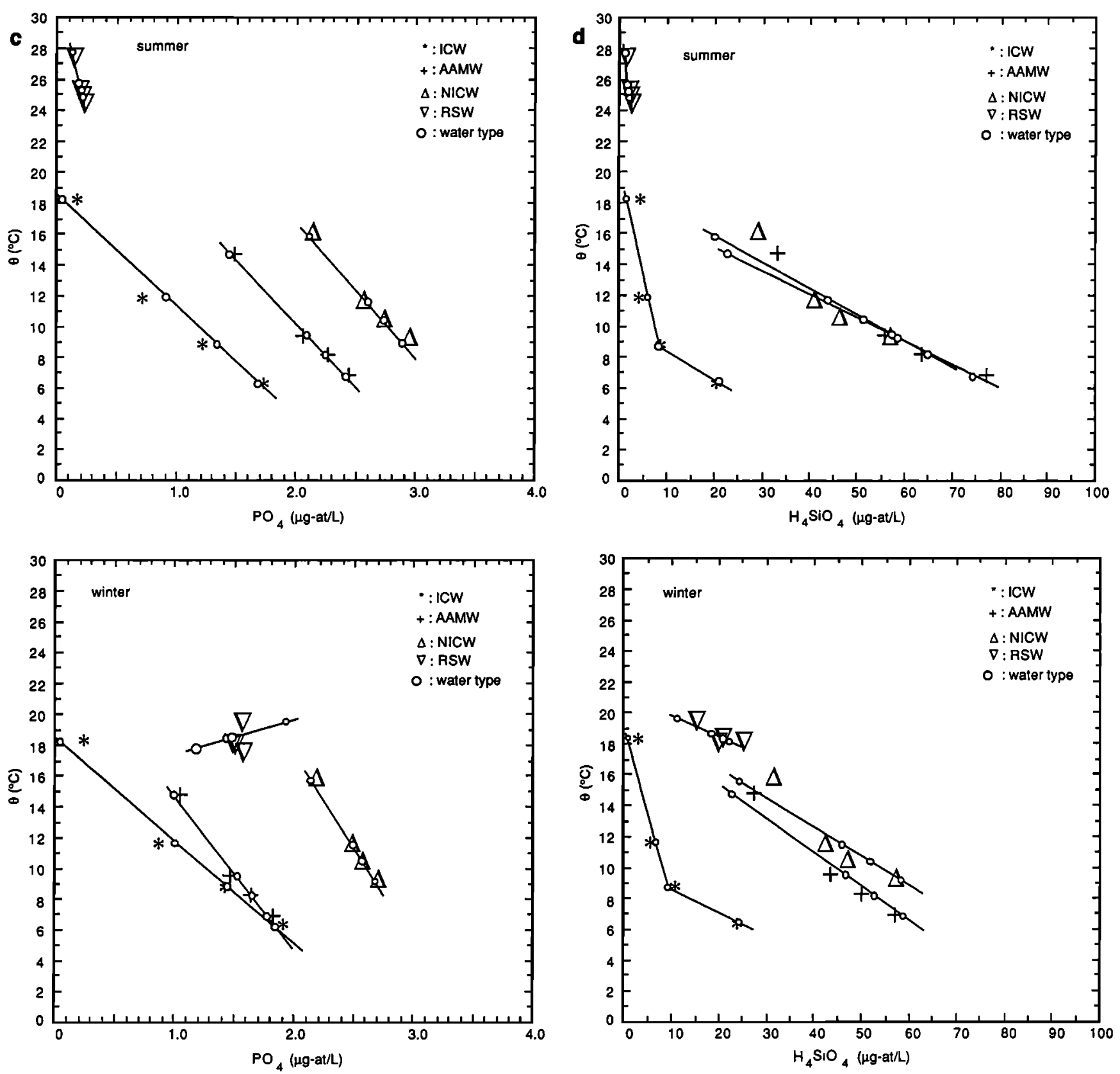

Figure 8. (continued)

Lanka and west of the Bay of Bengal (left panel) suggests the path of ICW into the Bay of Bengal during the summer. However, during the winter, the 10,20 , and $30 \%$ ICW contour lines south of Sri Lanka point to the west (right panel), suggesting an opposite flow. The $100 \%$ of ICW mixing ratio in the subtropical region points to it as its source region. The dense mixing ratio contours found east of $70^{\circ} \mathrm{E}$ at $15^{\circ} \mathrm{S}$ indicate the location of a strong hydrological front resulting from mixing between ICW and AAMW inflow.

A striking feature is found east of Madagascar. During the summer, the water mass contribution of ICW (see 70, 80, and 90\% contour lines) extends toward the south, suggesting a southward flow (Figure 9a, left panel). However, these contour lines evidently extend north during the winter (Figure 9a, right panel). The $60 \%$ line is especially noticeable that extends to north of Madagascar. This seasonal reverse is also evident in the mirror image of ICW, the NICW in the right panel of Figure $9 \mathrm{~b}$ and can be clearly seen in the lower surfaces.

Another interesting feature is found in the subtropics during the winter. The $100 \%$ contour line of ICW contribution retreats northward from the southern boundary (Figure 9a, right panel). This has been described before in the parameter distribution of section 3 and is a consequence of the northward invasion of lowtemperature and low-salinity water resulting from ice - melting and precipitation during austral summer in the Southern Ocean. If the southem boundary of the subtropical gyre retreats north and so does the Subtropical Convergence Zone, this seasonal change during winter might explain the occurrence of the reversed northward flow east of Madagascar. The afore mentioned seasonal feature of ICW mixing ratio distribution from Figure 9a suggests a rather clear picture of ICW spreading northward from the subtropics to the Bay of Bengal. During summer, ICW has to 
Table 2. Source Water Type Definitions and Parameter Weights for the Summer Monsoon

\begin{tabular}{|c|c|c|c|c|c|c|}
\hline Water Type & $\sigma_{\theta}$ & $\begin{array}{c}\text { Potential } \\
\text { Temperature, }{ }^{\circ} \mathrm{C}\end{array}$ & Salinity, psu & Oxygen, mL/L & $\begin{array}{c}\text { Phosphate, } \mu \mathrm{g} \text { - } \\
\text { atom } / \mathrm{L}\end{array}$ & $\begin{array}{l}\text { Silicate, } \mu g- \\
\text { atom } / \mathrm{L}\end{array}$ \\
\hline $\begin{array}{l}\text { ICW } \\
\text { ICW } \\
\text { ICW } \\
\text { NICW } \\
\text { NICW } \\
\text { AAMW } \\
\text { AAMW } \\
\text { RSW }\end{array}$ & $\begin{array}{l}25.7 \\
26.9 \\
27.1 \\
25.7 \\
27.1 \\
25.7 \\
27.1 \\
25.7\end{array}$ & $\begin{array}{l}18.15 \\
9.21 \\
6.56 \\
15.60 \\
9.29 \\
14.96 \\
6.73 \\
27.60 \\
(12.82)\end{array}$ & $\begin{array}{l}35.62 \\
34.79 \\
34.55 \\
34.84 \\
35.05 \\
34.64 \\
34.56 \\
39.21 \\
(12.82)\end{array}$ & $\begin{array}{l}5.94 \\
5.05 \\
4.79 \\
0.07 \\
0.52 \\
2.63 \\
2.30 \\
4.19 \\
(4.59)\end{array}$ & $\begin{array}{l}0.06 \\
1.29 \\
1.66 \\
2.13 \\
2.84 \\
1.41 \\
2.41 \\
0.12 \\
(0.85)\end{array}$ & $\begin{array}{l}1.57 \\
8.06 \\
21.39 \\
21.44 \\
58.59 \\
22.94 \\
80.08 \\
1.07 \\
(4.59)\end{array}$ \\
\hline
\end{tabular}

* Parameter weights are given in parentheses.

find its way flowing to the north far off east of Madagascar because of the existing apparent southward flow along east of Madagascar from the South Equatorial Current [Wyrtki, 1973]. ICW then takes its ways into the Bay of Bengal advected by the South Equatorial Current from the west, the Somali Current, and the Southwest Monsoon Current. During winter a northward path of ICW paralells the eastern Madagascar, as is suggested rather clearly by both parameter distribution and water - mass contribution. Because the western boundary current off the Somali coast is replaced by the North Equatorial Current pointing to the south, further northward flow of ICW has to be in the Equatorial Countercurrent.

Since NICW is interpreted as an aged ICW, the mixing ratio distribution of NICW can be used as a complementary explanation of the ICW transition path. The extension of NICW from the Bay of Bengal to Madagascar points clearly to the western Indian Ocean in Figure 9b. The dense contours in the eastern Indian Ocean suggest that southward flowing NICW is blocked by a strong inflow of AAMW. The right panel of Figure $9 \mathrm{~b}$ shows a large proportion of NICW flowing to the south during the northeast monsoon. In contrast, a tongue of NICW $50 \%$ contour off Somali coast suggests less NICW extending to the south during the summer, leaving more space for northward ICW to pass. AAMW flow is apparently strongest during the summer (Figure 9c, left panel). In summer the westward tongue of its mixing ratio extends as far as the eastern African coast line (Figure 9c, left panel). As mentioned before, property distributions, particularly that of silicate, on this density surface indicate that a communication between NICW in the Bay of Bengal and AAMW is unlikely during the southwest monsoon. We recognize a clear separation of the low silicate distribution between NICW and AAMW. However, property fields suggest that communication might be possible during the northeast monsoon. This conjecture is corffirmed by Figure 9c, which indicates a $20 \%$ mixture of AAMW flowing into the eastern Bengal Bay during the winter (right panel), but not during the summer (left panel). AAMW's spreading into the Bay of Bengal is probably by way of the Equatorial Countercurrent. Note that the mixing ratio pattern south of $30^{\circ} \mathrm{S}$ is due to invasion of Southern Ocean water which has the same characteristics as AAMW (see section 3), and should not be regarded as a contribution of AAMW.

Figure 9d shows the relative contributions of RSW/PGW on the $\sigma_{\theta}=25.7$ isopycnal surface during the two seasons. The way to estimate the relative contribution of RSW/PGW has been described before. The seasonal effect is documented by the water mass spreading patterns of RSW/PGW in the Arabian Sea. During the southwest monsoon, RSW/PGW contributes only $20 \%$ to the thermocline ventilation (left panel). The northward stretching of the $10 \%$ and $20 \%$ contour lines in the western Arabian Sea has implications for why RSW/PGW contributes so much less during the southwest monsoon. This is caused by a strong, jet-like western boundary Somali Current penetrating the western Arabian Sea. It effectively blocks the outflow of RSW/PGW. However, during the northeast monsoon, the western boundary current in the region is replaced by a southward monsoon current,

Table 3. Source Water Type Definitions and Parameter Weights for the Winter Monsoon

\begin{tabular}{lllllll}
\hline Water Type & $\sigma_{\theta}$ & $\begin{array}{c}\text { Potential } \\
\text { Temperature, }{ }^{\circ} \mathrm{C}\end{array}$ & Salinity, psu & Oxygen, mL/L & $\begin{array}{c}\text { Phosphate, } \mu \text { g- } \\
\text { atom/L }\end{array}$ & $\begin{array}{c}\text { Silicate, } \mu \text { g- } \\
\text { atom/L }\end{array}$ \\
\hline & & & & & & \\
ICW & 25.7 & 18.17 & 35.62 & 5.84 & 0.05 & 1.13 \\
ICW & 26.9 & 9.39 & 34.80 & 4.98 & 1.36 & 8.87 \\
ICW & 27.1 & 6.77 & 34.56 & 4.72 & 1.76 & 22.49 \\
NICW & 25.7 & 15.70 & 34.85 & 0.04 & 2.12 & 58.49 \\
NICW & 27.1 & 9.17 & 35.03 & 0.54 & 2.67 & 22.01 \\
AAMW & 25.7 & 14.93 & 34.63 & 2.62 & 0.97 & 58.67 \\
AAMW & 27.1 & 6.90 & 34.59 & 2.31 & 1.78 & $(2.12$ \\
RSW & 25.7 & 19.23 & 35.97 & 1.67 & 1.85 & $(0.67)$ \\
\end{tabular}

* Parameter weights are given in parentheses. 

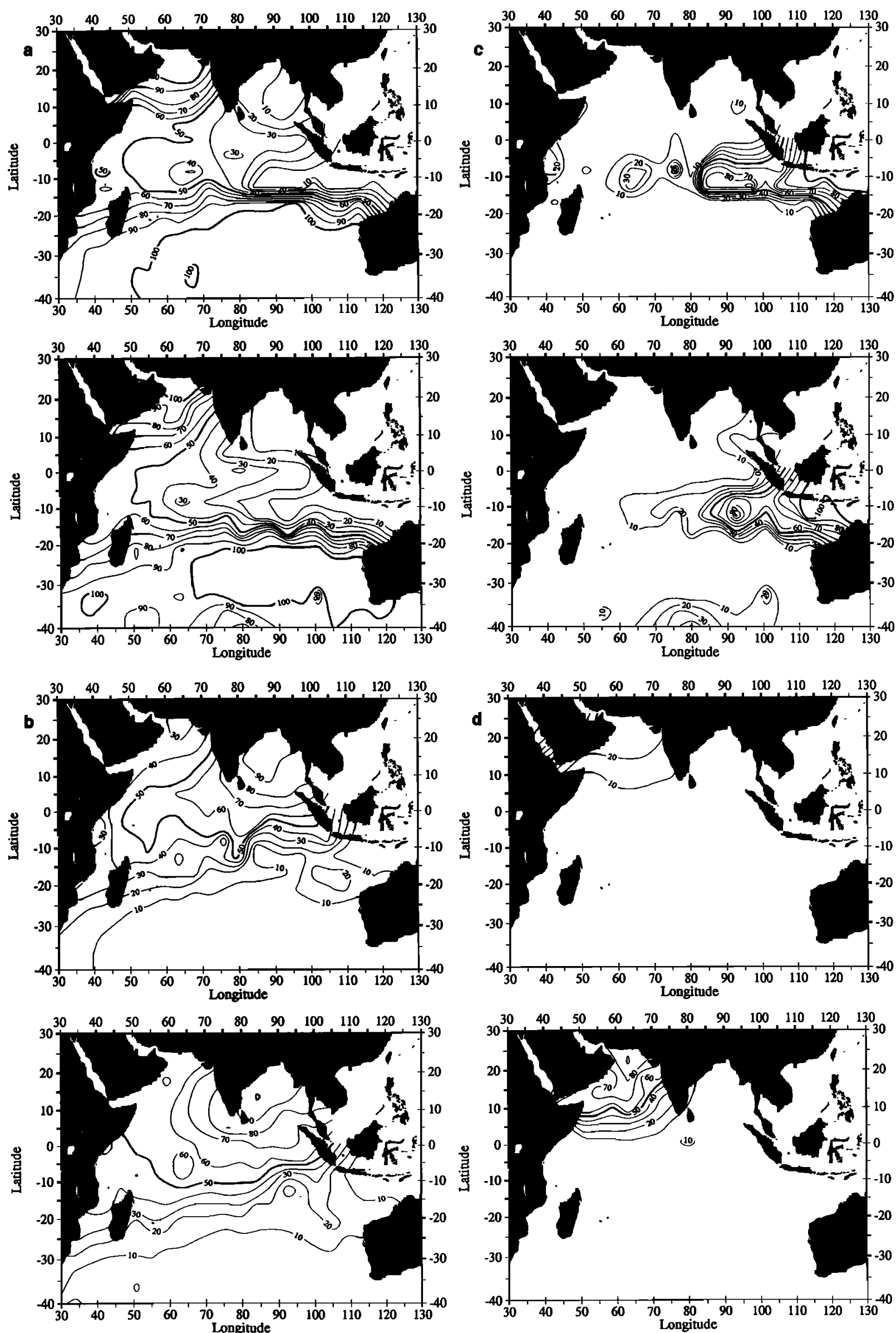

Figure 9. Water mass contributions on the $\sigma_{\theta}=25.7$ isopycnal surface for (left) the summer monsoon and (right) the winter monsoon: (a) the contribution of Indian Central Water (ICW), (b) the contribution of North Indian Central Water (NICW), (c) the contribution of Australasian Mediterranean Water (AAMW), and (d) the contribution of Red Sea Water (RSW)/Persian Gulf Water (PGW). 
the North Equatorial Current. Under northeasterly monsoonal forcing, RSW/PGW contributes much more to the thermocline ventilation during the winter (right panel), but its major contribution is still limited to the Arabian Sea region.

Water - mass features on the $\sigma_{\theta}=26.7$ isopycnal mixing surface show unexpected patterns. ICW again indicates stronger northward extension during the southwest monsoon (Figure 10a, left panel). Contour lines of percentage mixing ratio extend north of Cape Guardafui, Somali. In the northeastern Indian Ocean the $30 \%$ contour line approaches Sri Lanka more closely to than in the winter situation. The path of NICW during the southwest monsoon is depicted in the eastern Indian Ocean. At $10^{\circ} \mathrm{S}$ it turns toward the west (Figure 10b, left panel); there is not such a clear path during the winter (right panel). Interestingly, AAMW shows northward bending during the southwest monsoon (Figure 10c, left panel). However, no such tendency of the return movement is apparent during the northeast monsoon (right panel), even though AAMW is driven to as far as $5^{\circ} \mathrm{N}$. The distribution of the mixing ratio pattern is more zonal. The seasonal difference of AAMW contribution is probably due to this isopycnal-mixing-dominated surface. Under wind forcing of the southwest monsoon, the epipycnal advection of water - mass movement is certainly the strongest among the four isopycnal surfaces.

The northward bending of AAMW seen in the left panel of Figure $10 \mathrm{c}$ is not surprising if one looks back at the parameter distribution of section 3 on the same surface. The left panels of Figures $4 \mathrm{~d}, 4 \mathrm{e}$, and $4 \mathrm{f}$ show clear northward bending of oxygen $(1.5 \mathrm{~mL} / \mathrm{L})$, phosphate $(2.0 \mu \mathrm{g}-$ atom/L) and silicate $(30 \mu \mathrm{g}$ atom/L) contour lines south of Sri Lanka during the summer. One may ask why we do not see the northward bending of AAMW on the upper isopycnal surface, where property distribution also shows northward extension. A simple answer is that above surface, $\sigma_{\theta}=25.7$, is not an isopycnal-dominated surface, and diapycnal/dianeutral mixing has to be invoked [You, 1996].

One common point can be drawn during the two seasons in Figure 10c, namely, AAMW extends westward enough to be another source water of the western boundary current. These results in Figure 10 also support the transition path for ICW on this isopycnal surface proposed by You and Tomczak [1993]. The residual maps (the sum of total contributions of the source water types minus 100\%) in Figure 10d, show rather small residuals in most areas during the two seasons, except the subtropical region and the Arabian Sea. The Indian Ocean subtropical gyre region has a residual of $10 \%$ in the $\mathrm{ICW}$ formation region, suggesting that the ICW contribution can be overestimated by as much as $10 \%$. Much larger residuals are found in the Arabian Sea. This has a technical reason. RSW/PGW contributions were calculated as residuals from the mixing model. Nevertheless, we are confident with such an approach in our mixing model, since the residual maps of Figure 10d show that omitting RSW/PGW induces great errors. The large residuals are confined to the Arabian Sea.

Below the $\sigma_{\theta}=26.7$ surface the seasonal signals are weaker, though they do not disappear, as we have seen from the parameter distribution in section 3 . Of course, the thermocline circulation could be expected to be rather sluggish. This is especially true in the northern Indian Ocean. Because seasonal signals on the lower two isopycnal surfaces are not as apparent as those on the upper two surfaces, we have to analyze the subtle seasonal differences carefully. Moreover, because the residual during the winter (the right panels of Figures $11 \mathrm{~d}$ and 12d) is relatively larger than during the summer in the northern Indian Ocean, a spurious higher mixing ratio for the winter may sometimes occur. For example, with an ICW mixing proportion of $10 \%$ in the Bay of
Bengal in both panels of Figure 11a, a zero contribution is given when the residual of $10 \%$ during the winter (Figure 11d, right panel) is subtracted. However, with $5 \%$ of residual during the summer (Figure 11d, left panel) one derives an ICW contribution of $5 \%$. Therefore the seasonal difference of water - mass contribution needs to be analyzed in combination with the residual map. Taking a 5\% residual into account for both seasons in Figure $11 \mathrm{~d}$, we still find a relatively stronger summer signal (Figure 11a, left panel) in the northward flow of ICW at northeast of Madagascar (note the 70 and $60 \%$ contour lines) compared to the right panel of Figure 11d. However, we should keep in mind that one usually assumes only the surface layer to be controlled by the monsoon regime. This paper concerns the circulation below the surface down to the main thermocline. Although the mixing pattern of water - mass contributions in the upper thermocline has suggested a circulation more or less similar to that in the surface layer, we may not assume that there exists no countercurrent (opposite to the surface flow) in the lower thermocline. On the other hand, the stronger northward flow of ICW through the western boundary has to return to the south rather than pile up in the northern Indian Ocean and wait for the following opposite monsoon season to take it back to the south. Therefore the return flow is expected along the eastern boundary or in the lower thermocline.

The path of southward NICW is still seen clearly in the westem Indian Ocean (Figures 11b and 12b). Although AAMW is weaker in the lower thermocline, its westward cross-Indian Ocean flow and contribution to the Agulhas Current is shown clearly in Figures $11 \mathrm{c}$ and $12 \mathrm{c}$ for both seasons.

\section{2. Cross Sections}

You and Tomczak [1993] showed that ICW extends northward into the northern Indian Ocean with a high proportion of mixing ratios even in an annual mean situation. They suggest that the northward movement of ICW during the summer monsoon has therefore a much stronger impact on the thermocline circulation and ventilation. In other words, during the summer monsoon, under the strong southwesterly wind, a western boundary current, the Somali Current, develops and transports a large volume of water to the equatorial and northern Indian Ocean along Somali coast. The Southwest Monsoon Current, which is a continuation of the Somali Current, flows eastward and then turns to south merging with the South Equatorial Current. The South Equatorial Current, flowing westward with the throughflow of AAMW and northern subtropical gyre water, is enhanced, and most of its water recirculates into the Somali Current. It forms a wind-driven cyclonic gyre in the equatorial Indian Ocean, similar to the North Atlantic and North Pacific Ocean gyres. During the winter monsoon, under the northeasterly wind, the Somali Current disappears and is replaced by a reverse current, the North Equatorial Current, which carries a much smaller volume of water southward at a rather shallow depth [Wyrtki, 1973].

To show clearer evidences of seasonal variation of thermocline circulation and ventilation in the Indian Ocean, four cross sections, two meridional sections along $60^{\circ} \mathrm{E}$ and $90^{\circ} \mathrm{E}$ and two zonal sections along $10^{\circ} \mathrm{S}$ and $6^{\circ} \mathrm{N}$, are mapped on the basis of water-mass contribution already shown in Figures 9-12. Figure 13 is a meridional section at $60^{\circ} \mathrm{E}$ in the western Indian Ocean. A tongue-like structure of consistent northward extension of ICW is found during the summer at $300-400 \mathrm{~m}$ (Figure13a, left panel). However, the structure is not so apparent during the winter, especially, south of $15^{\circ} \mathrm{S}$ (right panel). There is an evidence that more ICW moves to the north in the upper $500 \mathrm{~m}$ of the western 

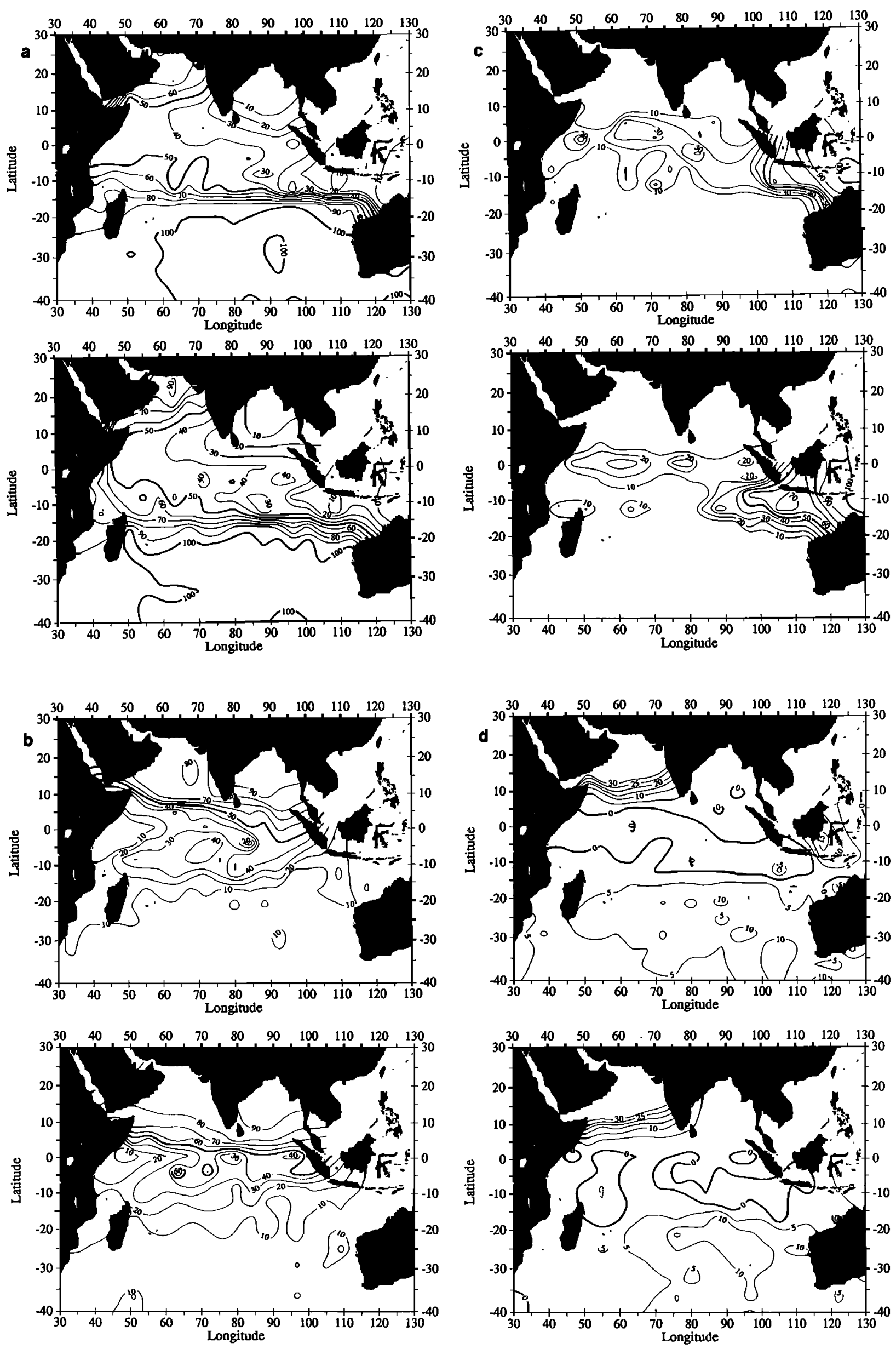

Figure 10. Water mass contributions on the $\sigma_{\theta}=26.7$ isopycnal surface (see Figure 9): (a) the contribution of ICW, (b) the contribution of NICW, (c) the contribution of AAMW, and (d) the distribution of residuals. 

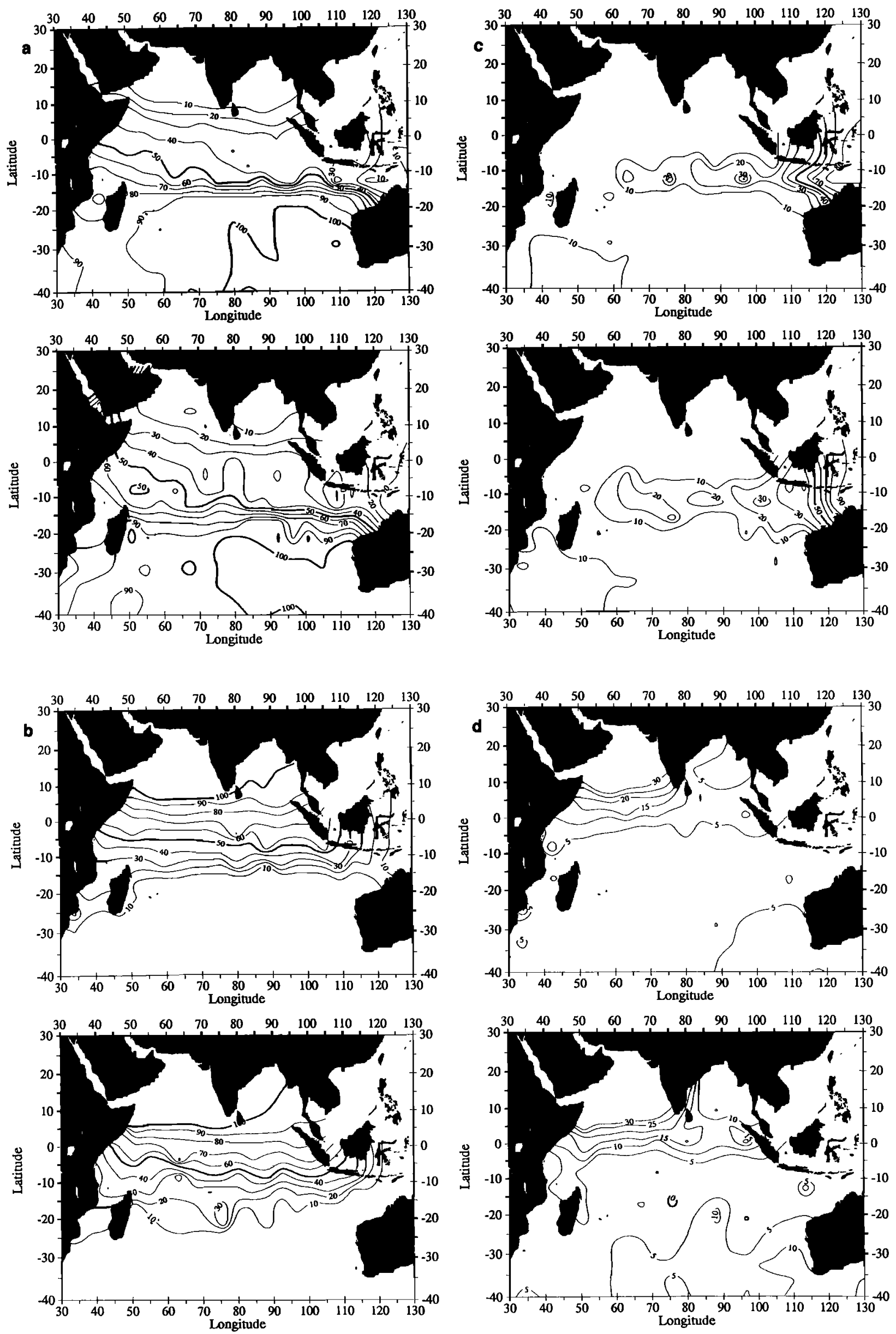

Figure 11. Water mass contributions on the $\sigma_{\theta}=26.9$ isopycnal surface (see Figure 9): (a) the contribution of ICW, (b) the contribution of NICW, (c) the contribution of AAMW, and (d) the distribution of residuals. 

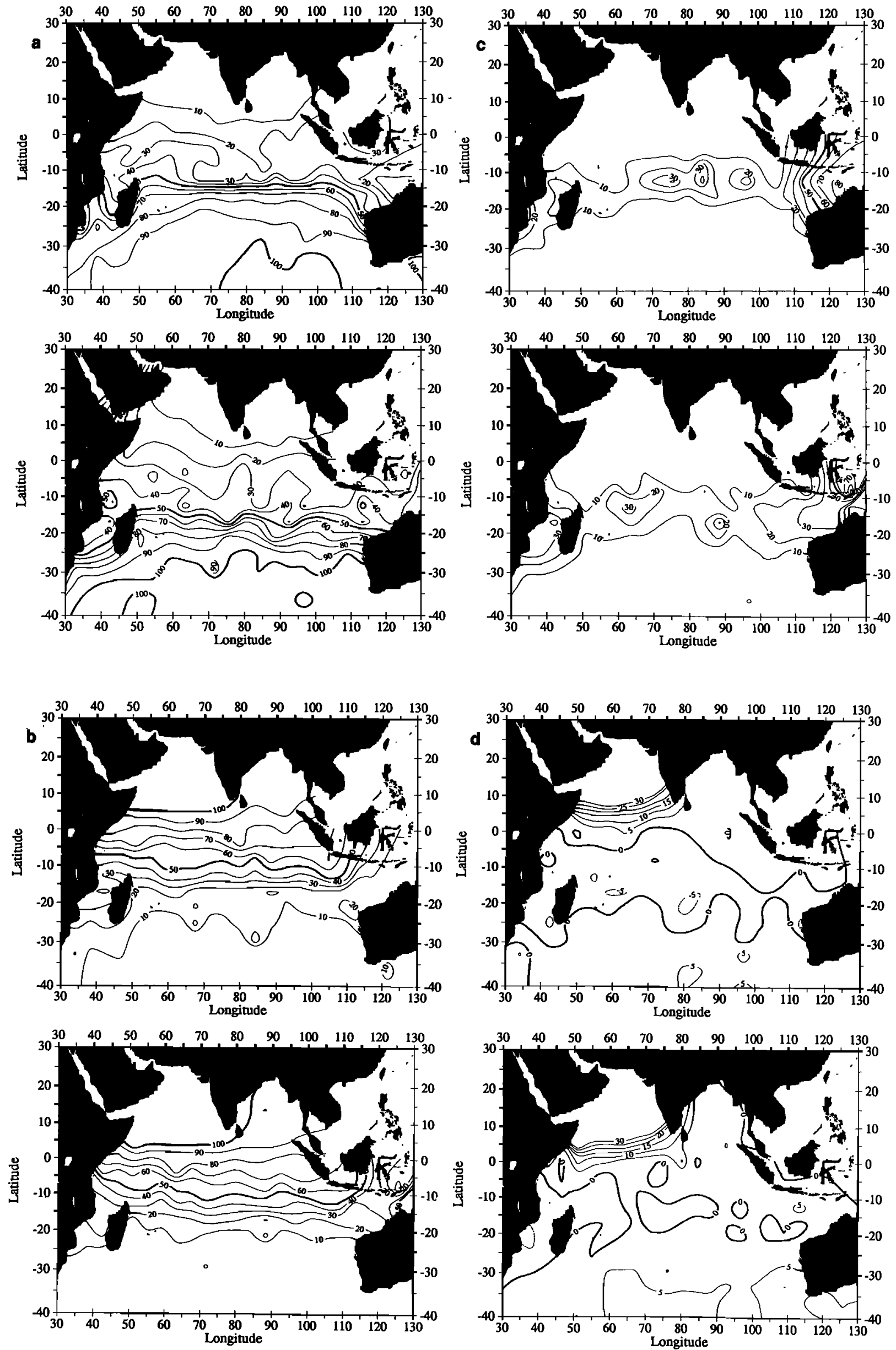

Figure 12. Water mass contributions on the $\sigma_{\theta}=27.1$ isopycnal surface (see Figure 9): (a) the contribution of ICW, (b) the contribution of NICW, (c) the contribution of AAMW, and (d) the distribution of residuals. 

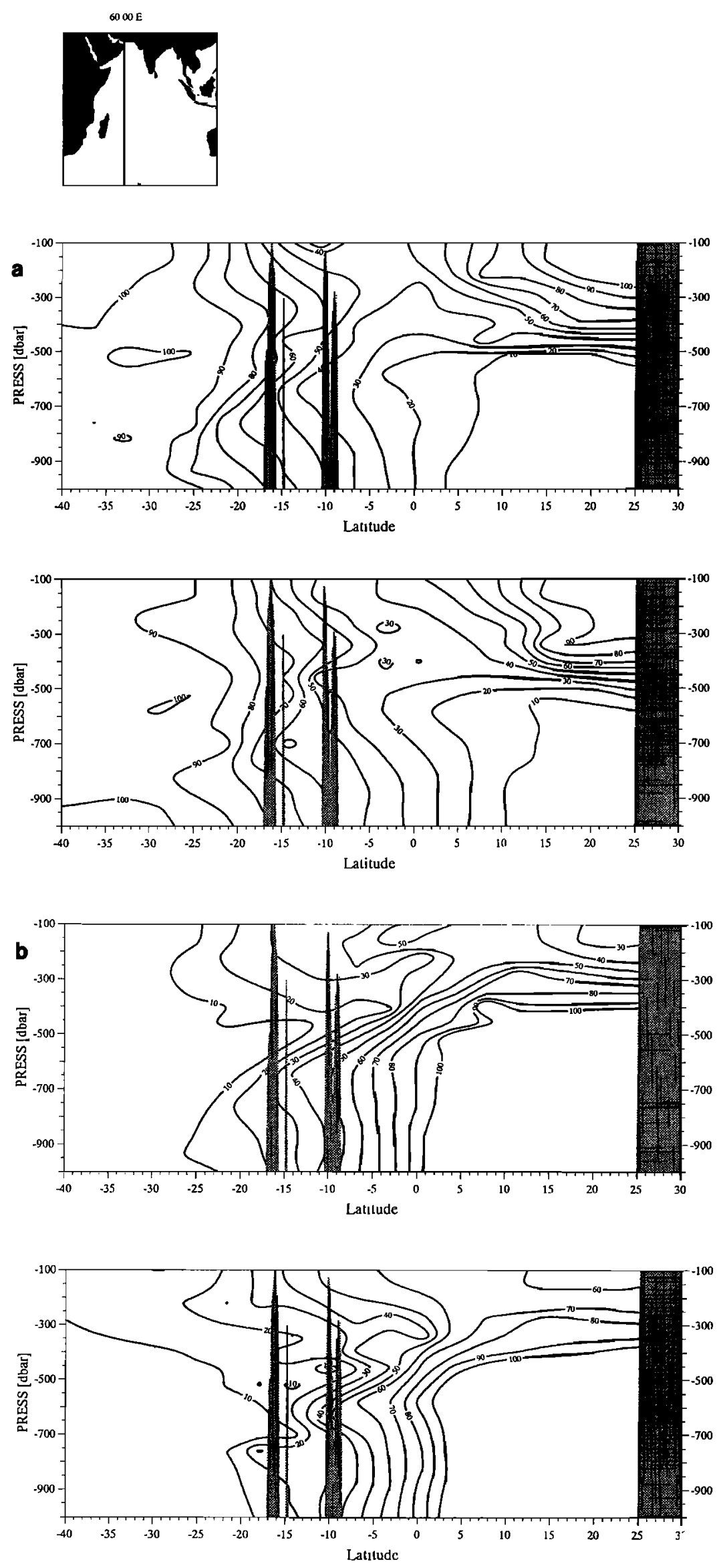

Figure 13. Water mass contributions in the western Indian Ocean along $60^{\circ} \mathrm{E}$ for (left) the summer monsoon and (right) the winter monsoon: (a) the contribution of ICW, (b) the contribution of NICW, and (c) the contribution of AAMW. 

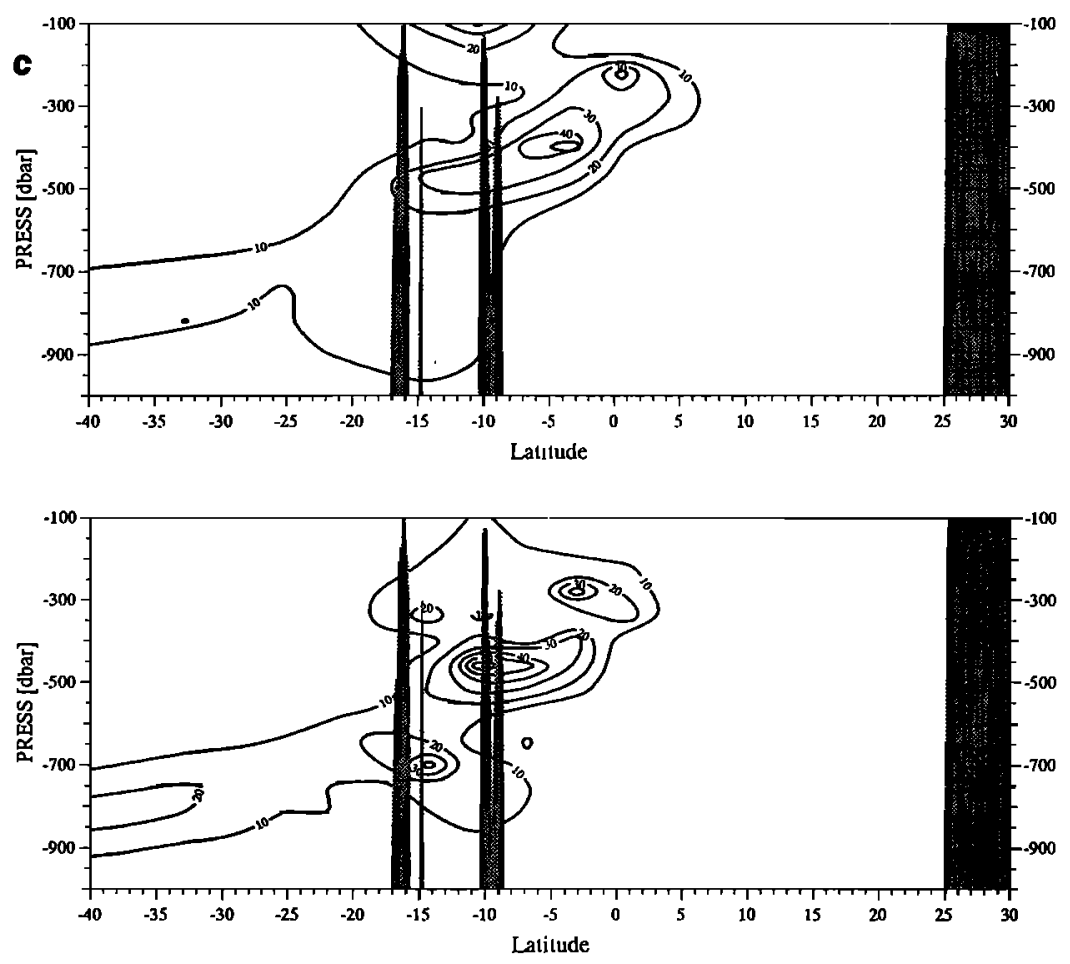

Figure 13. (continued)

Indian Ocean (note the difference in the 40 and $50 \%$ contour lines, north of $10^{\circ} \mathrm{S}$, between panels in Figure 13a). During winter, more NICW flows to the south in the western Indian Ocean (Figure 13b, right panel). Relatively higher contributions of AAMW are found in the upper $300 \mathrm{~m}$ of the thermocline at $10^{\circ} \mathrm{S}$ during the summer (Figure 13c, left panel). These results support Wyrtkis [1973] view that the summer monsoon has much stronger impact on thermocline water - mass than the winter monsoon and pronounced seasonal variation mainly occurs in the upper $400 \mathrm{~m}$.

In the eastern Indian Ocean at $90^{\circ} \mathrm{E}, \mathrm{ICW}$ does not show an apparent northward tongue during the summer (Figure 14a, left panel). The rather dense contour lines which are more vertically distributed suggest a front there that effectively blocks a northward penetration of ICW. As in Figure 13a, this front is significantly weaker in the western Indian Ocean. There is evidence that ICW is transported to the Bay of Bengal from the west during the summer, since about $10 \%$ of the ICW contribution is found in the upper thermocline north of $10^{\circ} \mathrm{N}$ (Figure 14a, left panel). This amount of ICW contribution is not seen during winter (right panel). The relatively stronger southward tongue of NICW in the left panel of Figure 14b at 300 $m$ has some implication for the return flow of the western boundary current during the summer. A clearer pattern was already shown in the left panel of Figure $10 \mathrm{~b}$ where a westward return flow is depicted in the eastern boundary region, merging with the South Equatorial Current. AAMW is slightly stronger, especially in the upper $300 \mathrm{~m}$, during the summer (Figure 14c, left panel). There seems to be some leakage of AAMW into the eastern Bay of Bengal. As described before, this leakage might occur when the water is advected into the eastern equatorial region by the Equatorial Countercurrent and prior to turning to a southward flow along western Sumatra.

Figure 15 shows a zonal section at $10^{\circ} \mathrm{S}$. The westward crossIndian Ocean flow of AAMW is approximately centered at this latitude. The $100 \%$ contribution east of $110^{\circ} \mathrm{E}$ in Figure $15 \mathrm{c}$ indicates the source region of AAMW. Relatively stronger influence during summer time is seen in the upper $300 \mathrm{~m}$ (Figure $15 \mathrm{c}$, left panel). Larger ICW percentage in the west, shown in Figure 15a, indicates the major pathway of ICW. A more apparent tongue of ICW mixing proportion in the left panel of Figure 15a suggests a stronger northward transition of ICW in the western boundary during the summer monsoon. The largest contribution of $70 \%$ near the African coast (Figure 15a, left panel) indicates the core of northward ICW at about $300 \mathrm{~m}$. To show more evidence of the stronger summer signal, another zonal section is chosen at $6^{\circ} \mathrm{N}$ (Figure 16). Therefore one can examine the flow pattern both in the west (at the Somali coast), where a strongest northward flow is expected, and in the east at Sri Lanka and in the eastern Bay of Bengal, where flow in and out of the bay can be compared. The left panel of Figure 16a shows that during the summer monsoon, northward ICW is stronger not only at the western boundary but also in the western Bay of Bengal. Note the 20 and $30 \%$ contour lines at $80^{\circ} \mathrm{E}$ in Figure 16a. The higher contribution of $20-30 \%$ in the eastern Bay of Bengal implies a flow pointing southward as a return of the northward flow entering from west of the bay. Interestingly, the left panel of Figure 16c shows about a $10-20 \%$ AAMW contribution to the westem boundary current at the Somali coast during the summer. A similar amount of AAMW is found surrounding Sri Lanka. In contrast, an AAMW contribution of about $20 \%$ evidently enters the eastern Bay of Bengal during the winter monsoon (right panel). Its path is probably by way of the South Equatorial Current and then the Equatorial Countercurrent, as described before.

\section{Summary and Discussion}

Using two seasonal hydrographic data sets in a mixing model of optimum multiparameter analysis combined with cluster analysis 

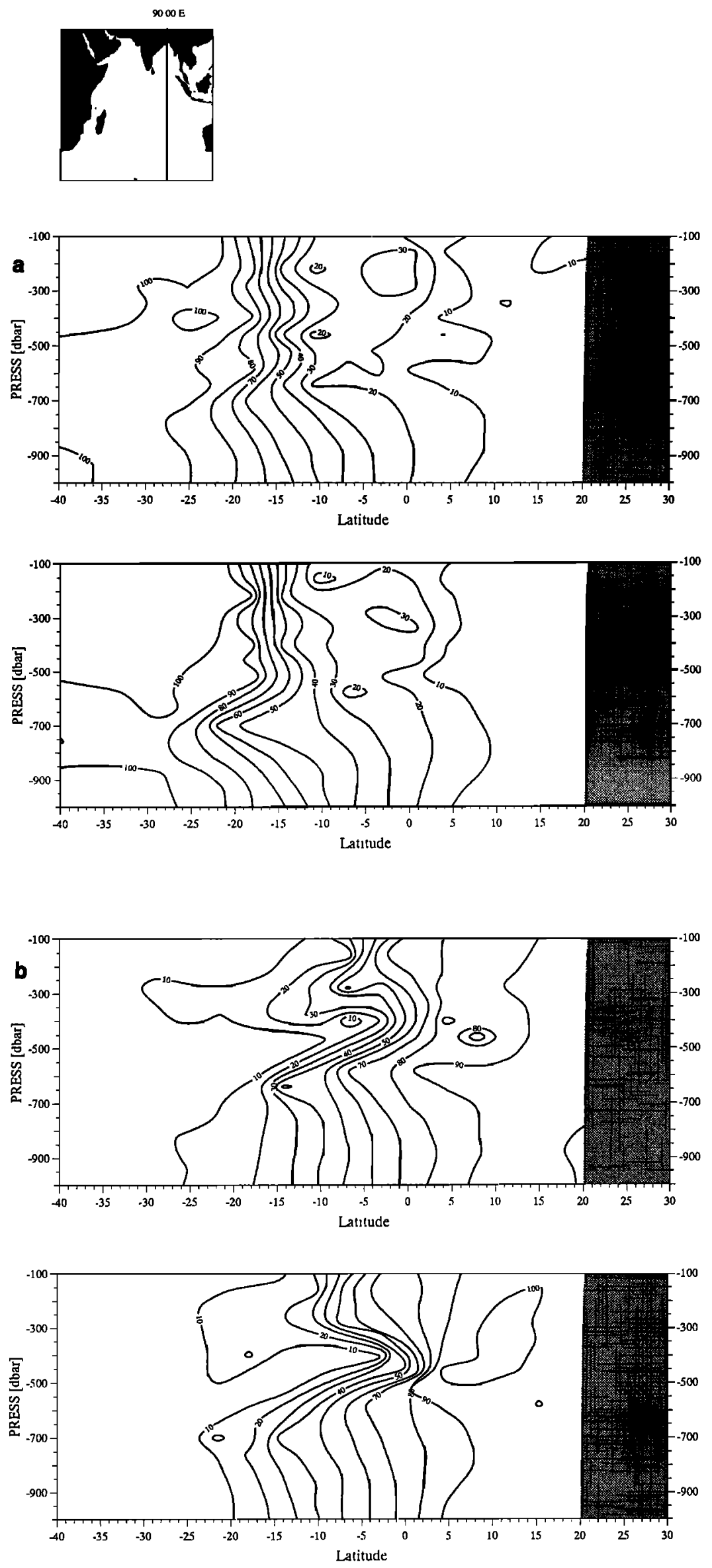

Figure 14. Same as Figure 13 but in the eastern Indian Ocean along $90^{\circ} \mathrm{E}$. 

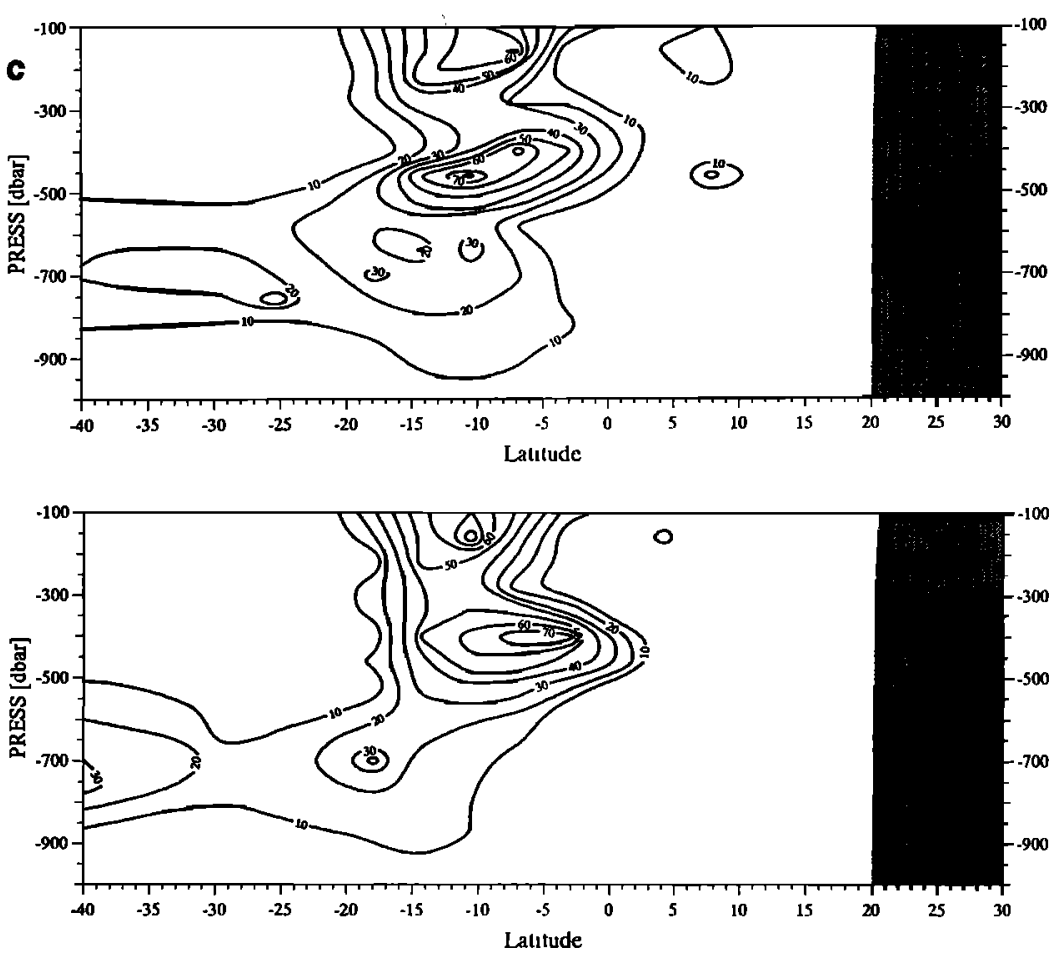

Figure 14. (continued)

has produced some significant results in this paper. Quantified water - mass mixing proportions on selected isopycnal surfaces showed large seasonal variations of thermocline circulation and ventilation in the Indian Ocean, especially prominent in the upper $400 \mathrm{~m}$. Cluster analysis became a useful tool for determining the initial source water types objectively. Fixing the sampling region in two overlapping clusters from two seasons guaranteed the accurate estimation of seasonal signals in the initial source water type definition and valid comparison of the signals. Water - mass mixing proportions which were quantified and mapped on isopycnal surfaces resulted in clear mixing patterns and spreading paths for each water mass. Seasonal variations of thermocline circulation and ventilation can thus be inferred from those mixing patterns.

However, the successful application of the method used in this paper still relies heavily upon skilled preconditioning. For example, without introducing the virtual water - mass, North Indian Central Water, one would derive very different mixing patterns in Figures 9-12 which could not be interpreted physically. Another difficulty occurs when the number of water types to be solved for mixing exceeds the number of known equations. For example, we had four source water masses, Indian Central Water, North Indian Central Water, Australasian Mediterranean Water and Red Sea Water/Persian Gulf Water, but only six equations. The decision was made to keep Red Sea Water/Persian Gulf Water out of the model as residual. Fortunately, such an approach did not cause a significant bias of the model results, since the large residual is confined to only the Arabian Sea in the upper thermocline. Of course, such an approach might have eliminated the possibility of Red Sea Water spreading to the south in the lower thermocline. In fact, this has to be considered when one or two additional parameters were available for the model analysis.

Nevertheless, a picture of seasonal variation of the Indian thermocline circulation and ventilation emerges from our study.
When these newly derived results are combined with previous studies, a clear schematic summer and winter thermocline circulation in the Indian Ocean is derived (Figure 17). Figure 17a shows the summer thermocline circulation, and Figure 17b shows its winter equivalent. Before interpreting the diagrams, we need to discuss some broad conditions. First, currents and eddies advect waters from their source regions and are mixed with other waters. Therefore the nomenclature for water - mass and current should be distinguished. In Figure 17 we have depicted names for water masses near their source regions, while names for currents are marked along streamlines. Second, one usually names currents as permanent flows without reversing their directions during the year. As we know, the Indian Ocean represents an exception, since the reversal monsoon regimes and their impact on currents are very profound. Those monsoonally controlled currents exert a profound effect throughout the thermocline. Therefore we retain those frequently used names such as the "Southwest Monsoon Current," "North Equatorial Current," "Equatorial Countercurrent", and for the western boundary current, "Somali Current." The East Madagascar Current [Tchernia, 1980; Rochford, 1966] is usually described as a southward flow along the eastem Madagascar. However, results from this paper suggest a flow reversal toward the north during the winter (austral summer). We therefore give the name only to its southward flow during the northern summer, similar to the situation for the Somali Current. Since the currents east and west of India change dramatically with the monsoon reversal, we tend not to name those currents.

During northern summer (Figure 17a), Indian Central Water is formed northward along the subtropical front and carried to the subtropics by the South Indian Ocean Current [Lutjeharms and Van Ballegooyen, 1984; Stramma, 1992]. Park et al. [1993] argued to use a more classic name, the Agulhas Return Current. The South Indian Ocean Current has several northward paths. In the southwestern Indian Ocean those northward flows form 

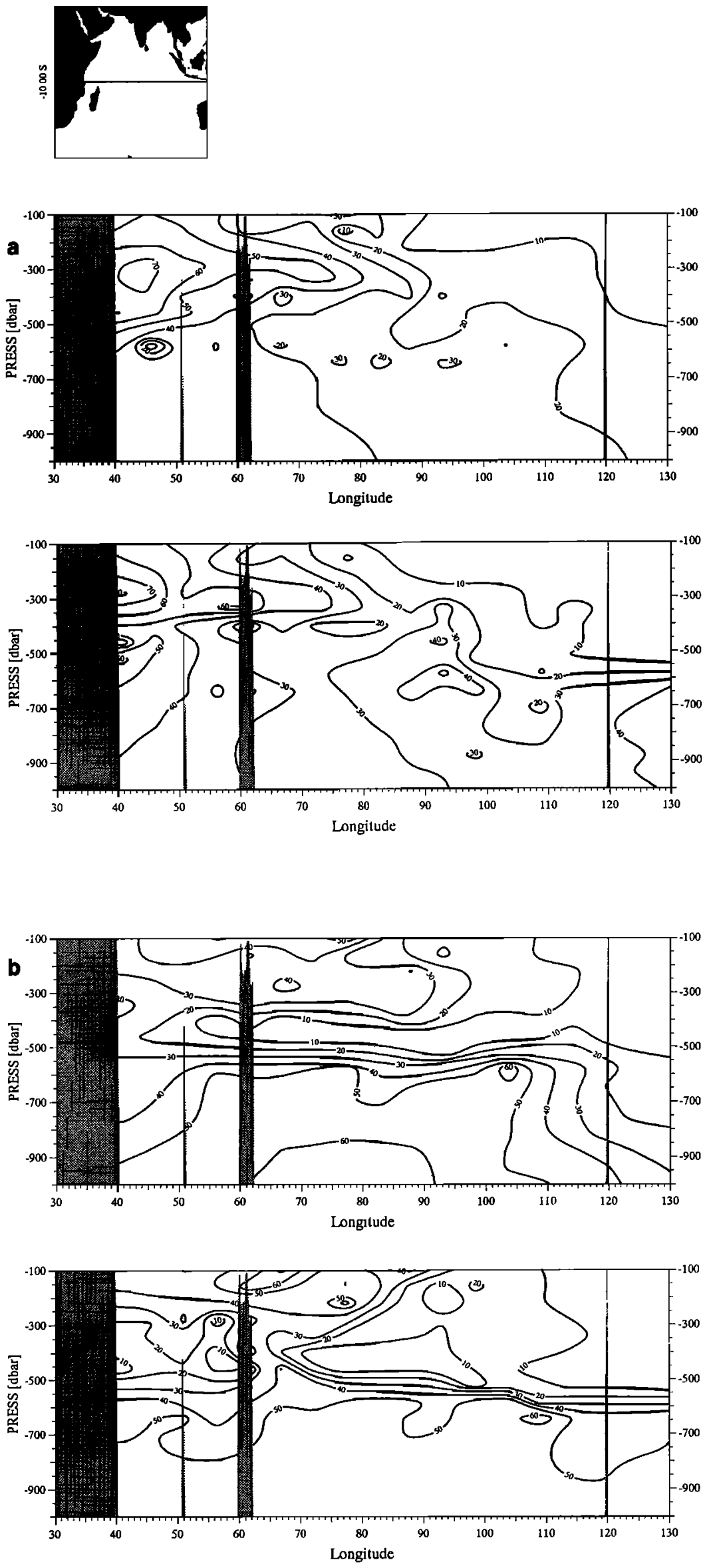

Figure 15. Same as Figure 13 but for a zonal section along $10^{\circ} \mathrm{S}$. 

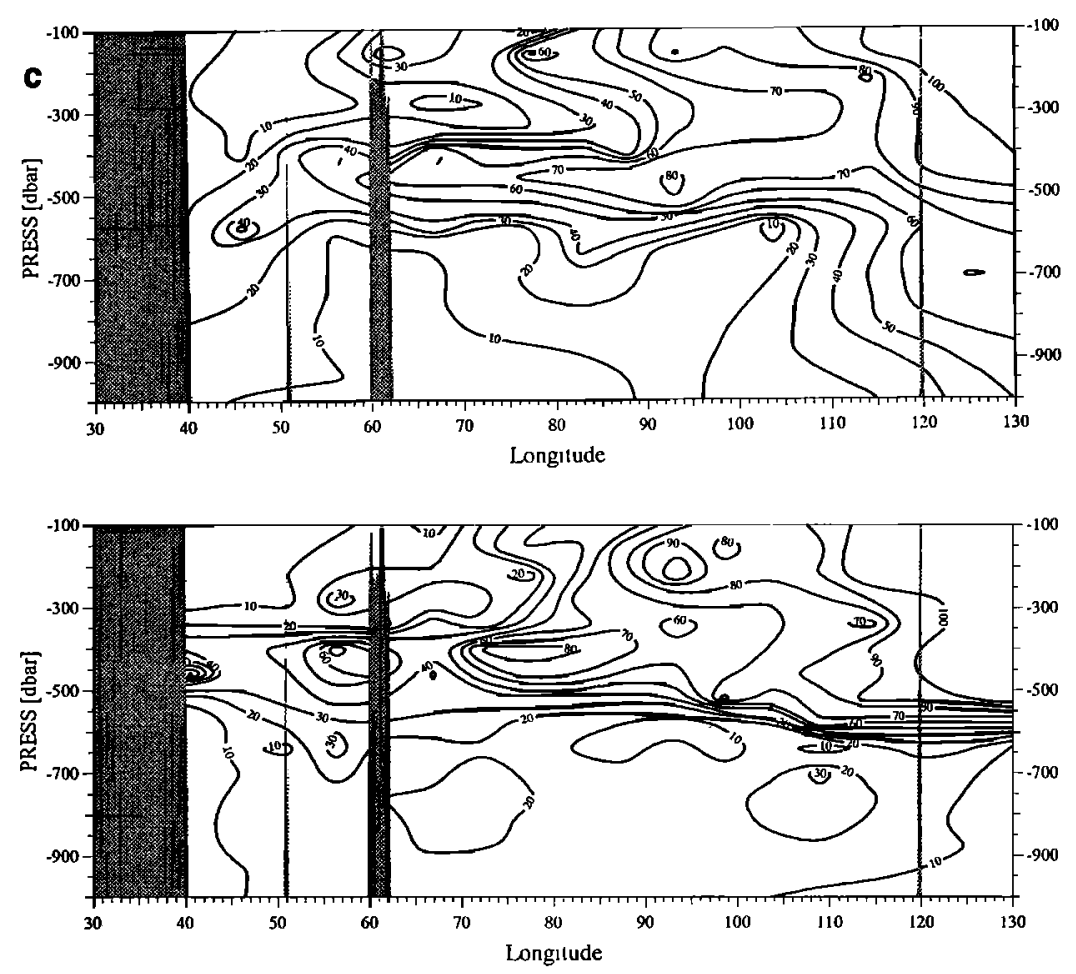

Figure 15. (continued)

recirculation cells locally feeding the Agulhas Current. In the central basin, some branches of the South Indian Ocean Current point to the north. Its easternmost extension is continued northward by the West Australia Current [Rochford, 1967]. East of the West Australia Current there should be a southward flow near the West Australia coast. There indeed exists a southward flow called the Leeuwin Current [Cresswell and Golding, 1980]. However, the Leeuwin Current may be too shallow to have a significant impact on the large-scale thermocline circulation below. Anyhow, we symbolically include a possible southward flow there to balance the northward West Australia Current near the West Australia coast without naming it. Indian Central Water is carried to the west by the South Equatorial Current. Some part of its water returns to the southwest Indian Ocean, forming a subtropical gyre and supplying the Agulhas Current. Part of it is carried north of Madagascar in a path probably far offshore of eastern Madagascar. It flows east of the southward East Madagascar Current. Further northward progress of Indian Central Water occurs by way of the East Africa Coastal Current [Swallow et al., 1991]. Indian Central Water then enters the equatorial and northern Indian Ocean in the western boundary current, the Somali Current, and part is carried to the eastern Indian Ocean by the Southwest Monsoon Current which is a broad eastward flow. The remainder of the western boundary current flows farther to the north. It parallels the western Arabian Sea in the East Arabian Current [Tomczak and Godfrey, 1994] and then turns southeastward, west of India, as part of the Southwest Monsoon Current. Indian Central Water ends its northward joumey entering the Bay of Bengal from west and east of Sri Lanka.

The southward retum route of Indian Central Water starts from the eastern Bay of Bengal, southward in the Sumatra-Java Current [Rochford, 1967]. Indian Central Water returns westward, enhancing the South Equatorial Current. A large part of it feeds back into the western boundary current. It forms a cylonic gyre similar to the North Atlantic and North Pacific [Wyrtki, 1973]. Some part of Indian Central Water in the South Equatorial Current merges with the East Madagascar Current. It flows through Mozambique Channel as the Mozambique Current. In balancing the southward Mozambique Current, the West Madagascar Current [Tchernia, 1980] is a rather permanent northward flow, although it is largely an anticyclonic feature [Wyrtki, 1973; Tchernia, 1980]. The return flow of Indian Central Water complets its loop in the Agulhas Current, most of which returns back to the Indian Ocean as the South Indian Ocean Current. A small part of it penetrates into the Atlantic as the warm water route. It compensates for the North Atlantic Deep Water absorbed and advected by the Antarctic Circumpolar Current south of Africa [Gordon, 1986].

The circulation of Australasian Mediterranean Water begins with a zonal flow westward crossing the Indian Ocean. Australasian Mediterranean Water is carried westward first by the Indonesian Throughflow (a current name, to be distinguished from the name Australasian Mediterranean Water used for water mass) and then merges into the South Equatorial Current, which bends somewhat to the north under stronger southwest monsoonal forcing. Northeast of Madagascar, Australasian Mediterranean Water contributes part of its water to the Agulhas Current through the East Madagascar Current and the Mozambique Current. The remainder supplies the Somali Current through the East Africa Coastal Current. Wyrtki [1973] suggested that about two thirds of the South Equatorial Current passes north of Madagascar and one - third turns to the south along the east coast of Madagascar (East Madagascar Current). The northward path of Australasian Mediterranean Water resembles the Indian Central Water route. We did not give a return route for Australasian Mediterranean Water, since Australasian Mediterranean Water is a net inflow water from the Pacific to the Indian Ocean. This is correct at least 

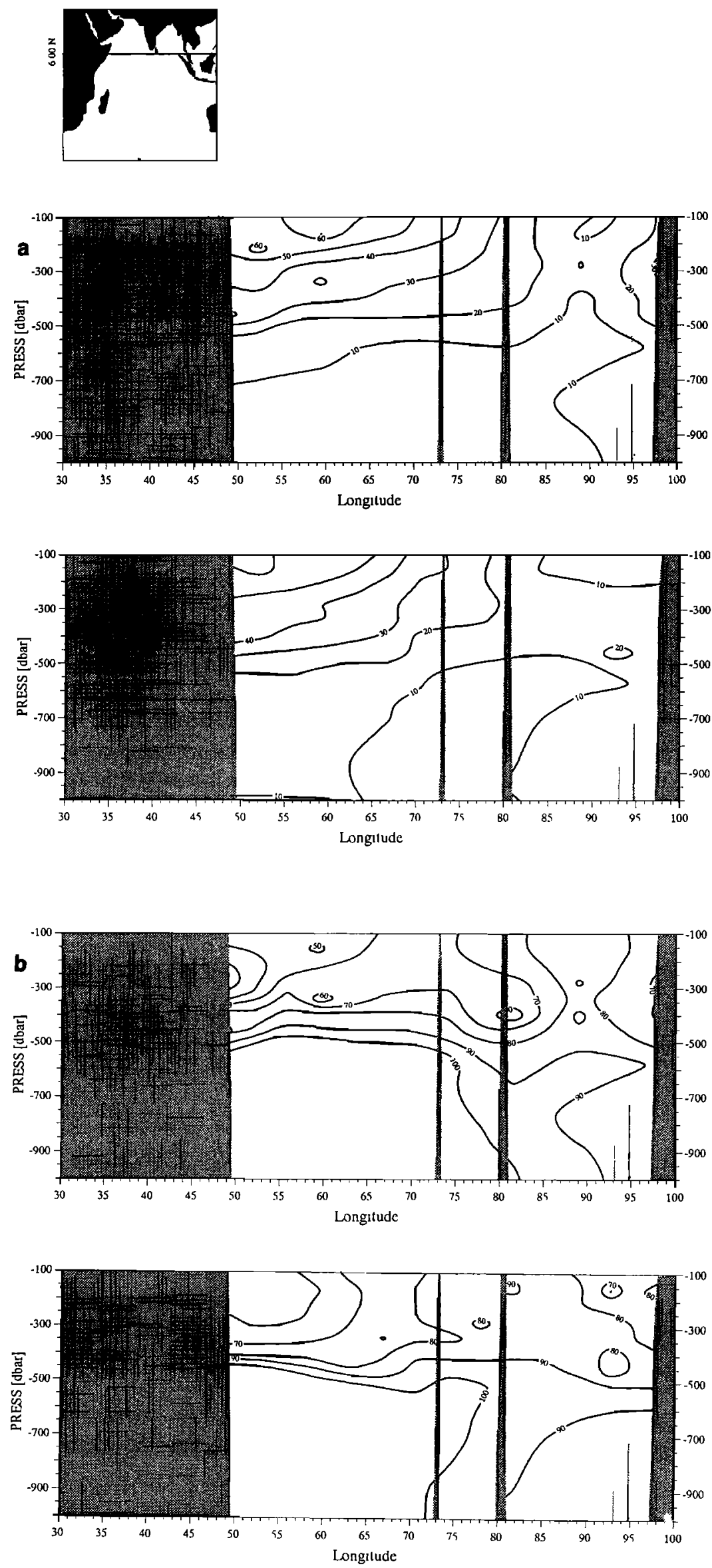

Figure 16. Same as Figure 13 but for a zonal section along $6^{\circ} \mathrm{N}$. 

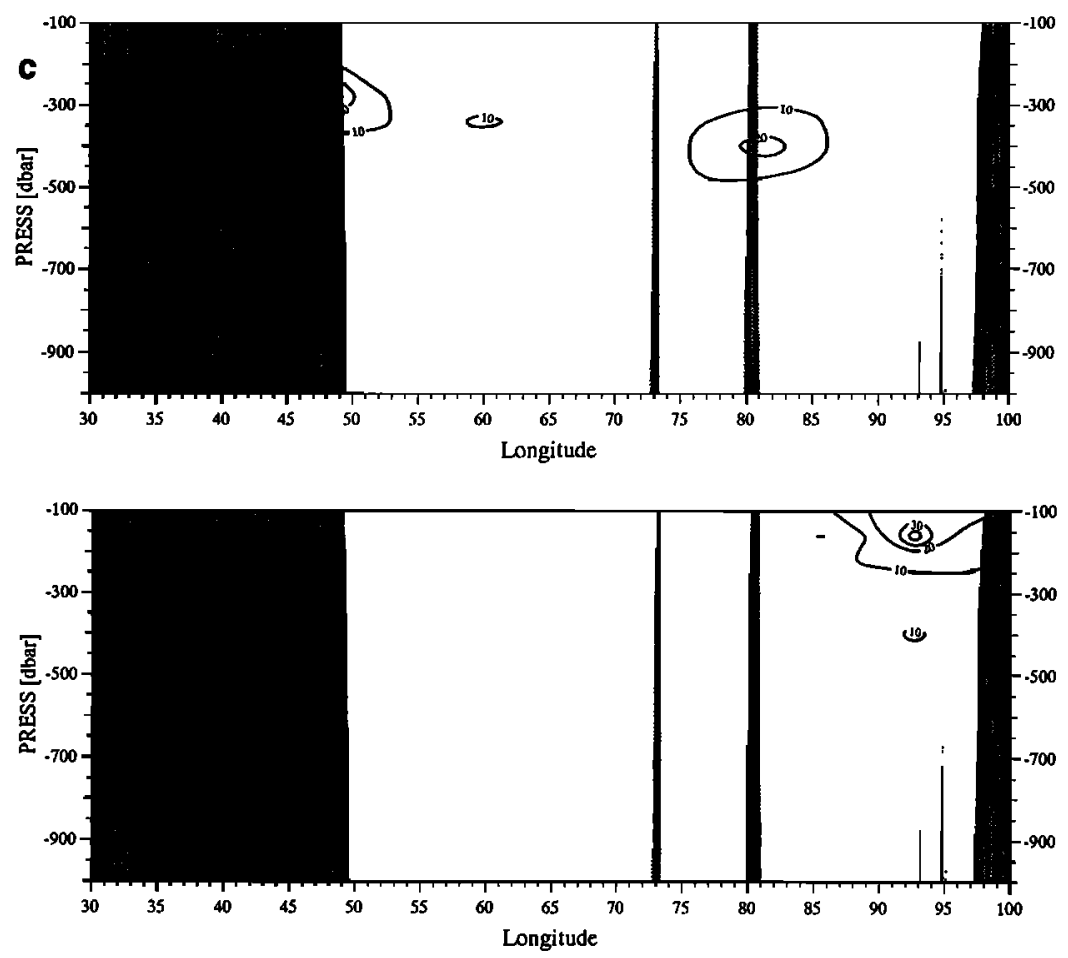

Figure 16. (continued)

in depth range of the thermocline. In the deeper level (below 1000 m), Fieux et al. [1994] did find an opposite flow, but even averaging from the surface down to $1900 \mathrm{dbar}$, they still got a net transport of $18.6 \pm 7 \mathrm{~Sv}\left(1 \mathrm{~Sv}=10^{6} \mathrm{~m}^{3} \mathrm{~s}^{-1}\right)$ flowing into the Indian Ocean from the Pacific.

During northern winter (Figure 17b), the South Indian Ocean Current bends to the north and so does the subtropical front, a factor already pointed out by Sverdrup et al. [1942], though they did not name this current. The northward shift of the subtropical front during the winter causes the flow east of Madagascar to reverse northward. Therefore the East Madagascar Current vanishes during the northern winter. As we saw before, the westward flow of Australasian Mediterranean Water is slightly weaker during the winter in the upper thermocline. One branch of the southward flow of the South Equatorial Current seems to split far off East Madagascar. This in turn adds some weight to the reversed flow east of Madagascar. A radical change in the thermocline circulation during the winter is the disappearance of the Somali Current, which is replaced by a southward flow of the North Equatorial Current. Indian Central Water then has to take

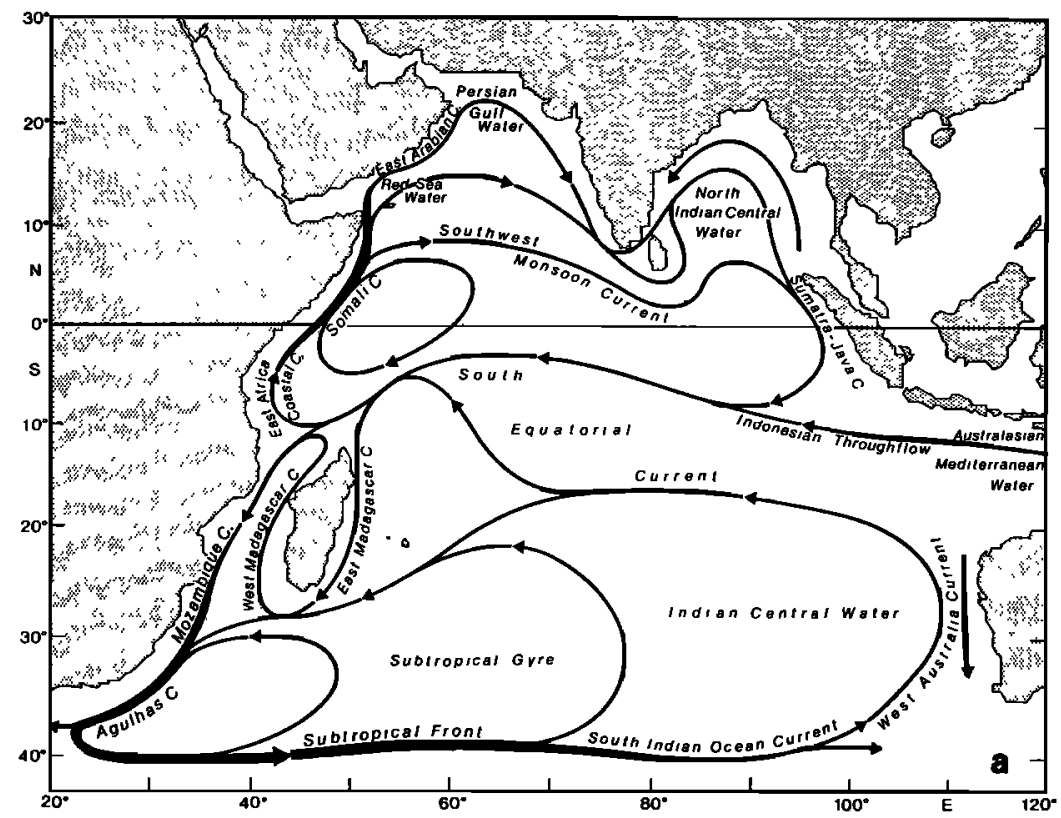

Figure 17. Schematic (a) summer and (b) winter thermocline circulation in the Indian Ocean. 


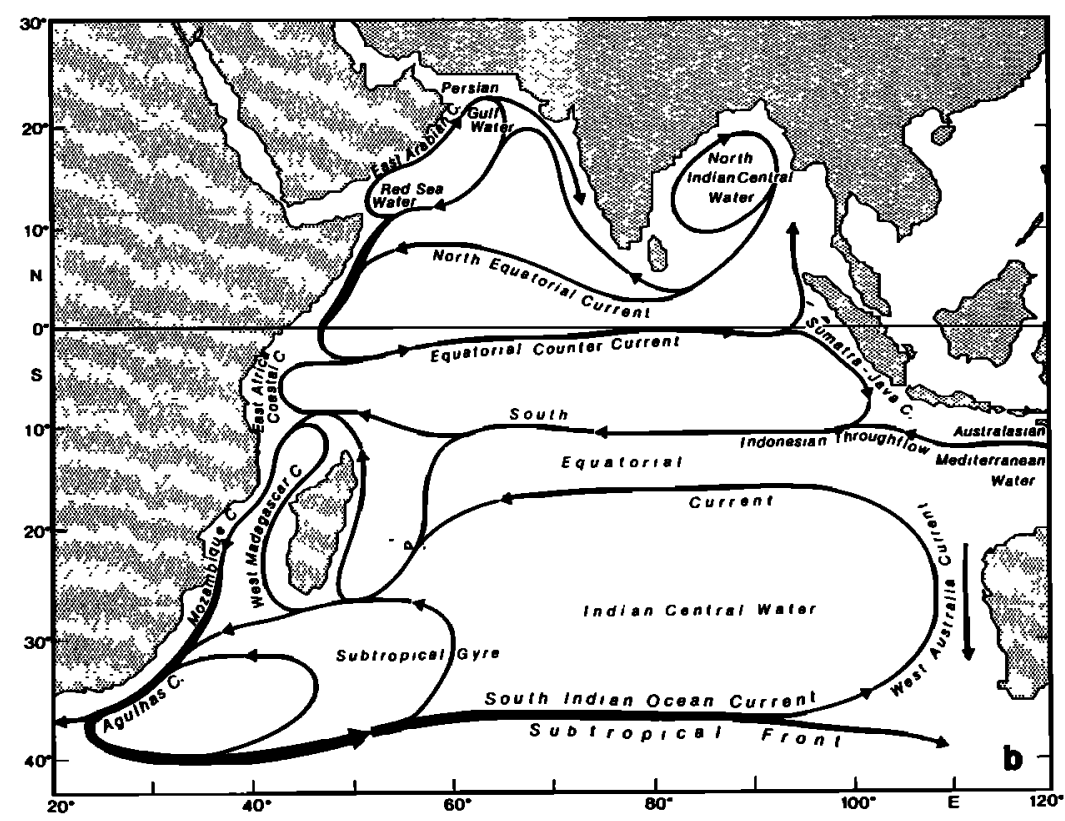

Figure 17. (continued)

its way in the Equatorial Countercurrent. Results from this study suggest some leakage of the Equatorial Countercurrent into the eastem Bay of Bengal. This leaves a possibility for the source to feed the westward North Equatorial Current from the east and to form a loop. As described before, this leakage occurs when the water is transported into the eastern equatorial Indian Ocean by the Equatorial Countercurrent. Most of the Equatorial Countercurrent then turns southward and becomes the SumatraJava Current. Nevertheless, about $10 \%$ of Indian Central Water and $10-20 \%$ of Australasian Mediterranean Water leak into the eastern Bay of Bengal in the upper thermocline as seen in Figure 16.

Wyrtki [1973] suggested that some low-salinity water originates from the Bay of Bengal flowing westward during the northeast monsoon. One branch continues westward along $5^{\circ} \mathrm{N}$, and the other northwestward along the coast of India. Shetye et al. [1991] also observed this low-salinity water of the Bengal Bay origin off West India. In the Arabian Sea, Tomczak and Godfrey [1994] found a cyclonic eddy-like flow during the winter. Therefore the East Arabian Current should still exist. It points to the north from the Gulf of Aden. These studies further indicate a southwestward flow across the central Arabian Sea. This conjecture is commensurate with the water - mass spreading paths in the right panels of Figures 9a, 9d, and 10a.

The above schematic summer and winter thermocline circulation is gathered from the parameter distributions and patterns of large-scale water - mass mixing and spreading on selected isopycnal surfaces. It has not yet been combined fully with observed velocity fields and transports, although basic observed flow paths of currents have been inferred. The schematics in Figure 17 therefore can only be a guide to possible flow paths of the thermocline waters of the Indian Ocean and their seasonal changes with the monsoon regime.

Acknowledgments. This study started at the School of Earth Science, Flinders University of South Australia, Adelaide, Australia and was finished during my stay as a visiting investigator at Institut für Meereskunde an der Universität Kiel, Germany. I thank John Toole for the CD29 data, Donald Olson for the MASAI data and Daniel Jarnous for the INDIGO data. Some archived data were collected during my visit to Massachusetts Institute of Technology. Some suggestion from T. Müller is acknowledged about the presentation of the final sketch. Figure 17, which was nicely drawn by A. Eisele. Constructive comments from two anonymous reviewers, especially the second reviewer, were very helpful in improving the presentation of the results.

\section{References}

Colborn, J. G., The Thermal Structure of the Indian Ocean, 173 pp., Univ. of Hawaii Press, Honolulu, 1975.

Cox, M. D., A baroclinic numerical model of the world ocean: Preliminary results, in Numerical Models of Ocean Circulation, 364 pp., Natl. Acad. Press, Washington, D. C., 1975.

Cresswell, G. R., and T. J. Golding, Observations of a south-flowing current in the southeastern Indian Ocean, Deep - Sea Res., part A, 27, 449-466, 1980.

Defant, A., Physical Oceanography, vol. I., 729 pp., Pergamon, Tarrytown, N. Y., 1961.

Emery, W. J., and J. Meincke, Global water masses: Summary and review, Oceanol. Acta, 9, 383-391, 1986.

Fieux, M., C. Andrié, P. Delecluse, A. G. Ilahude, A. Kartavtseff, F. Mantisi, R. Molcard, and J. C. Swallow, Measurements within the Pacific-Indian Oceans throughflow region, Deep - Sea Res. Part I, 41, 1091-1130, 1994

Gordon, A. L., Interocean exchange of thermocline water, J. Geophys. Res., 91, 5037-5046, 1986.

Jamous, D., L. Mémery, C. Andrie, P. Jean-Baptiste, and L. Merlivat, The distribution of helium 3 in the deep western and southem Indian Ocean, J. Geophys. Res., 97, 2243-2250, 1992.

Lutjeharms, J. R. E., and R. C. Van Ballegooyen, Topographic control in the Agulhas Current system, Deep - Sea Res., 31, 1321-1337, 1984.

Mackas, D. L., K. L. Denman, and A. F. Bennett, Least - squares multiple tracer analysis of water mass composition, J. Geophys. Res., 92, 29072918,1987

Mamayev, O. I., Temperature-Salinity Analysis of World Ocean Waters, 174 pp., Elsevier, New York, 1975.

McCartney, M. S., Subantarctic mode water, in A Voyage of Discovery, Genrge Deacon 70th Anniversary Volume, edited by M. Angel, pp. 103-109, Pergamon, Tarrytown, N. Y., 1977.

Olson, D. B., G. L. Hitchcock, R. A. Fine, and B. A. Warren, Maintenance of the low-oxygen layer in the central Arabian Sea, Deep - Sea Res., 40, 673-685, 1993.

Park, Y.-H., L. Gamberoni, and E. Charriaud, Frontal structure, water masses, and circulation in the Crozet Basin, J. Geophys. Res., 98, 12,361-12,385, 1993. 
Quadfasel, D. R., and F. Schott, Water-mass distribution at intermediate layers off the Somali coast during the onset of the southwest monsoon, J. Phys. Oceanogr., 12, 1358-1372, 1982.

Rochford, D. J., Distribution of Banda Intermediate Water in the Indian Ocean, Aust. J. Mar. Freshwater. Res., 17, 61-76, 1966.

Rochford, D. J., The phosphate levels of the major surface currents of the Indian Ocean, Aust. J. Mar. Freshwater. Res., 18, 1-22, 1967.

Sharma, G. S., Transequatorial movement of water masses in the Indian Ocean, J. Mar. Res., 34, 143-154, 1976.

Shetye, S. R., A. D. Gouveia, S. S. C. Shenoi, G. S. Michael, D. Sundar, A. M. Almeida, and K. Santanam, The coastal current off western India during the northeast monsoon, Deep - Sea Res., 38, 1517-1529, 1991.

Stramma, L., The South Indian Ocean Current, J. Phys. Oceanogr., 22, 421-430, 1992.

Sverdrup, H. U., M. W. Johnson, and R. H. Fleming, The Oceans, Their Physics, Chemistry and General Biology, 1087 pp., Prentice-Hall, Englewood Cliffs, N. J., 1942.

Swallow, J. C., F. Schott, and M. Fieux, Stracture and transport of the East African Coastal Current, J. Geophys. Res., 96, 22,245-22,257, 1991.

Tchemia, P., Descriptive Regional Oceanography, 253 pp., Pergamon, Tarrytown, N. Y., 1980.

Tomczak, M., A multiparameter extension of temperature/salinity diagram techniques for the analysis of non-isopycnal mixing, Prog. Oceanogr., 10, 147-171, 1981.

Tomczak, M., and J. S. Godfrey, Regional Oceanography: An Introduction, 422 pp., Pergamon, Tanytown, N. Y., 1994.

Tomczak, M., and D. Large, Optimum multiparameter analysis of mixing in the thermocline of the east Indian Ocean, J. Geophys. Res., 94, 16141-16149, 1989.
Toole, J. M., and B. A. Warren, A hydrographic section across the subtropical South Indian Ocean, Deep - Sea Res., 40, 1973-2019, 1993.

Warren, B. A. Transindian hydrographic section at lat. $18^{\circ} \mathrm{S}$ : Property distributions and circulation in the South Indian Ocean, Deep - Sea Res., Part A, 28, 759-788, 1981.

Warren, B. A., H. Stommel, and J. C. Swallow, Water masses and patterns of flow in the Somali Basin during the southwest monsoon of 1964, Deep - Sea Res., 13, 825-860, 1966.

Wyrtki, K., Scientific results of marine investigations of the South China Sea and the Gulf of Thailand 1959-1961. Naga Rep.. 2, 195 pp., Scripps Inst. of Oceanogr., Univ. of Calif., San Diego, La Jolla, 1961.

Wyrtki, K., Oceanographic Atlas of the International Indian Ocean Expedition, 531 pp., Natl. Sci. Found., Washington, D. C., 1971.

Wyrtki, K., Physical oceanography of the Indian Ocean, in Ecological Studies: Analysis and Synthesis, vol. 3, edited by B. Zeitzschel, pp. 1836, Springer-Verlag, New York, 1973.

You, Y., Dianeutral mixing in the thermocline of the Indian Ocean, Deep - Sea Res., 43, 291-320, 1996.

You, Y., and M. Tomczak, Thermocline circulation and ventilation in the Indian Ocean derived from water mass analysis, Deep-Sea Res. 40, 1356, 1993.

Y. You, Center for Climate System Research, University of Tokyo, 4-61 Komaba, Meguro-ku, Tokyo 153, Japan.

(Received June 14, 1995; revised September 13, 1996; accepted October 17, 1996.) 